\title{
RESEARCH
}

Open Access

\section{Biophysical classification of a CACNA1D de novo mutation as a high-risk mutation for a severe neurodevelopmental disorder}

\author{
Nadja T. Hofer ${ }^{1}$, Petronel Tuluc ${ }^{1}$, Nadine J. Ortner ${ }^{1}$, Yuliia V. Nikonishyna ${ }^{1}$, Monica L. Fernándes-Quintero ${ }^{2}$,
} Klaus R. Liedl ${ }^{2}$, Bernhard E. Flucher ${ }^{3}$, Helen Cox ${ }^{4}$ and Jörg Striessnig ${ }^{1 *}$ (D)

\begin{abstract}
Background: There is increasing evidence that de novo CACNA1D missense mutations inducing increased Cav1.3 Ltype $\mathrm{Ca}^{2+}$-channel-function confer a high risk for neurodevelopmental disorders (autism spectrum disorder with and without neurological and endocrine symptoms). Electrophysiological studies demonstrating the presence or absence of typical gain-of-function gating changes could therefore serve as a tool to distinguish likely diseasecausing from non-pathogenic de novo CACNA1D variants in affected individuals. We tested this hypothesis for mutation S652L, which has previously been reported in twins with a severe neurodevelopmental disorder in the Deciphering Developmental Disorder Study, but has not been classified as a novel disease mutation.
\end{abstract}

Methods: For functional characterization, wild-type and mutant Cav1.3 channel complexes were expressed in tsA201 cells and tested for typical gain-of-function gating changes using the whole-cell patch-clamp technique.

Results: Mutation S652L significantly shifted the voltage-dependence of activation and steady-state inactivation to more negative potentials $(\sim 13-17 \mathrm{mV})$ and increased window currents at subthreshold voltages. Moreover, it slowed tail currents and increased $\mathrm{Ca}^{2+}$-levels during action potential-like stimulations, characteristic for gain-offunction changes. To provide evidence that only gain-of-function variants confer high disease risk, we also studied missense variant S652W reported in apparently healthy individuals. S652W shifted activation and inactivation to more positive voltages, compatible with a loss-of-function phenotype. Mutation S652L increased the sensitivity of Cav1.3 for inhibition by the dihydropyridine L-type $\mathrm{Ca}^{2+}$-channel blocker isradipine by 3-4-fold.

Conclusions and limitations

Our data provide evidence that gain-of-function CACNA1D mutations, such as S652L, but not loss-of-function mutations, such as $5652 \mathrm{~W}$, cause high risk for neurodevelopmental disorders including autism. This adds CACNA1D to the list of novel disease genes identified in the Deciphering Developmental Disorder Study. Although our study does not provide insight into the cellular mechanisms of pathological Cav1.3 signaling in neurons, we provide a unifying mechanism of gain-of-function CACNA1D mutations as a predictor for disease risk, which may allow the establishment of a more reliable diagnosis of affected individuals. Moreover, the increased sensitivity of S652L to isradipine encourages a therapeutic trial in the two affected individuals. This can address the important question to which extent symptoms are responsive to therapy with $\mathrm{Ca}^{2+}$-channel blockers.

Keywords: Autism spectrum disorder, Neurodevelopmental disorder, CACNA1D, Gain-of-function mutation, L-type $\mathrm{Ca}^{2+}$-channels

\footnotetext{
* Correspondence: Joerg.Striessnig@uibk.ac.at

${ }^{1}$ Department of Pharmacology and Toxicology, Centre for Molecular

Biosciences, University of Innsbruck, Innrain 80/82, 6020 Innsbruck, Austria

Full list of author information is available at the end of the article
}

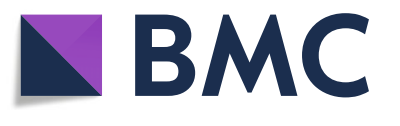

(c) The Author(s). 2020 Open Access This article is distributed under the terms of the Creative Commons Attribution 4.0 International License (http://creativecommons.org/licenses/by/4.0/), which permits unrestricted use, distribution, and reproduction in any medium, provided you give appropriate credit to the original author(s) and the source, provide a link to the Creative Commons license, and indicate if changes were made. The Creative Commons Public Domain Dedication waiver (http://creativecommons.org/publicdomain/zero/1.0/) applies to the data made available in this article, unless otherwise stated. 


\section{Background}

In electrically excitable cells, $\mathrm{Ca}^{2+}$ inward current through voltage-gated $\mathrm{Ca}^{2+}$-channels (VGCCs; Cav) contributes to membrane depolarization and plays a key role in coupling electrical activity to intracellular $\mathrm{Ca}^{2+}$ dependent signaling processes (for review, see [1-3]). Therefore, VGCCs control essential physiological processes, such as hormone secretion, muscle contraction, sinoatrial node pacemaking, and sensory function. In the brain, they trigger neurotransmitter release, shape neuronal excitability, and couple excitation to gene expression associated with synaptic plasticity and different types of learning and memory [1,3-5]. VGCC activity is fine-tuned to the specific requirements of cellular functions. This is accomplished by the functional heterogeneity and diverse subcellular targeting of ten poreforming $\alpha_{1}$-subunit isoforms [6], several accessory $\beta$ and $\alpha_{2} \delta$-subunits as well as by alternative splicing and post-translational modification (for a review, see [3]).

L-type $\mathrm{Ca}^{2+}$ channels (LTCCs; Cav1) form one of the three main families of VGCCs. From the four members (Cav1.1-Cav1.4), Cav1.2 and Cav1.3 are expressed in most electrically excitable cells, including a wide variety of brain regions [3]. Both are located post-synaptically at somatodendritic locations and serve a key role in activity-dependent gene transcription [1,3,5]. Genetic variants in both channels have been associated with neuropsychiatric disease risk. Multiple common intronic single nucleotide polymorphisms (SNPs) in Cav1.2 (CACNA1C gene) LTCCs have consistently been associated with bipolar disorder and schizophrenia, although the consequences of these polymorphisms for Cav1.2 function remain unknown (for review, see [7-9]). Very rare de novo CACNA1C missense mutations cause Timothy Syndrome, a severe disease with lethal arrhythmias, facial dysmorphism, syndactyly and autism spectrum disorder (ASD) in surviving patients [10-12]. Together these findings have triggered new interest in clinical trials to repurpose LTCC blockers (" $\mathrm{Ca}^{2+}$-antagonists"), licensed as antihypertensive drugs since decades, also for the treatment of mood disorders [13].

We [14-16] and others [17-20] have recently provided accumulating evidence that de novo missense mutations in the pore-forming $\alpha_{1}$-subunit of Cav1.3 LTCCs (CACNA1D) confer high risk for neurodevelopmental disorders in humans. Symptoms range from ASD with (mutations A749G, Q547H [14, 20];) and without (G407R [14]) intellectual disability to more severely affected patients with seizures, muscle hypotonia, and global developmental delay (V401L [15]). Some patients also exhibit additional endocrine symptoms (primary aldosteronism or hyperinsulinism; G403D, I750M [17, 18]) due to the expression of Cav1.3 in adrenal zona glomerulosa cells and pancreatic $\beta$-cells (for a review, see [3]).
Our studies revealed that all these genetic variants are not present in healthy parents or unaffected siblings and are absent in 141,456 reference genomes of controls without pediatric disease (gnomAD database, [21]). This is consistent with high penetrance and strongly supports a likely causative role of these mutations. Moreover, electrophysiological analysis of six mutations (from seven of these patients) after expression in HEK-293 cells revealed a highly consistent pattern of functional changes: they all induce gating changes that can enhance Cav1.3 $\mathrm{Ca}^{2+}$-current through these channels, in particular at subthreshold voltages. This gain-of-function is evident from a drastic slowing of channel inactivation and/ or by facilitation of channel opening at more negative voltages [16]. Therefore, the demonstration of such typical gain-of-function gating changes in functional studies may allow to distinguish likely pathogenic from nonpathogenic CACNA1D missense variants and help in the genetic diagnosis of individuals with neurodevelopmental disorders. This appears necessary because several genetic studies failed to classify CACNA1D missense variants as high-risk mutations and $C A C N A 1 D$ as a high-risk gene for neurodevelopmental disorders, including ASD [14, 15, 22, 23]. For example, gain-of-function CACNA1D mutation G407R in a patient with ASD has been identified, but has not been classified as high-risk mutation. However, functional analysis revealed typical gain-of-function changes, which strongly support its pathogenic potential [14].

In contrast to de novo gene-disrupting mutations (nonsense, splice site, frameshift), which cause a protein loss-of-function, the prediction of the pathogenic potential of missense variants is more difficult because in most cases their functional consequences cannot be predicted by bioinformatics tools. While our data argue for a high disease risk due to Cav1.3 gain-of-function, heterozygous de novo CACNA1D variants resulting in a loss of Cav1.3 activity are unlikely to cause human disease. This is strongly supported by previous findings both in knockout mice (for a review, see [3]) and Cav1.3-deficient humans with sinoatrial node dysfunction and deafness (SANDD; OMIM \#614896 [24, 25]), in which functional loss of one or both CACNA1D alleles did not lead to a central nervous system (CNS) disease phenotype. This complicates the classification of new CACNA1D variants as high-risk mutations in genetic studies.

Here, we provide further convincing evidence for the high disease risk of gain-of-function de novo CACNA1D mutations for neurodevelopmental disorders. This is shown for mutation S652L, which has previously been identified in the Deciphering Developmental Disorders study, in a cohort of individuals with a severe developmental disorder of unknown cause [23]). However, in this study, it has not been 
classified as novel disease mutation with compelling evidence for pathogenicity and therefore CACNA1D has not been included as one of the 12 novel highrisk genes. Moreover, we demonstrate that a rare variant at the same position, $\mathrm{S} 652 \mathrm{~W}$, induces a gating defect compatible with a loss-of-function, which explains its presence in apparently healthy individuals. Our data should raise awareness for the pathogenic potential of CACNA1D mutations, especially in patients without additional congenital endocrine symptoms as diagnostic features. De novo CACNA1D missense mutations may be underdiagnosed in clinical practice.

\section{Methods}

\section{Complementary DNA constructs}

Human wild-type (WT) Cav1.3 $\alpha_{1}$-subunits contained either exons $8 \mathrm{a}$ and $42\left(\mathrm{WT}_{\mathrm{L}}\right.$; long C-terminal splice variant; Genbank accession number: EU363339) or exons $8 \mathrm{a}$ and $43_{\mathrm{S}}\left(\mathrm{WT}_{\mathrm{S}}\right.$; short C-terminal splice variant [26];). All constructs were previously cloned into a pGFP $^{\text {minus }}$ vector containing a CMV promoter, an ampicillin resistance gene and no GFP tag as described [26, 27].

Cloning of $\mathrm{S} 652$ constructs $\mathrm{S}_{652 \mathrm{~L}}, \mathrm{~S} 652 \mathrm{~L}_{\mathrm{S}}$, and $\mathrm{S}_{652 \mathrm{~W}}$ : To introduce mutations $\mathrm{S} 652 \mathrm{~L}$ or $\mathrm{S} 652 \mathrm{~W}$ into various Cav1.3 splice variants SOE PCR was used. Briefly, nt 1685-4059 of $\mathrm{WT}_{\mathrm{L}}$ or $\mathrm{WT}_{\mathrm{S}}$ were PCR amplified with overlapping primers (primer pair 1 and 2) introducing the point mutations $\mathrm{C}>\mathrm{T}$ (Ser $>$ Leu) or $\mathrm{C}>\mathrm{G}$ (Ser $>$ Trp) at position nt 1967 in separate PCR reactions (PCR a and b) using $\mathrm{WT}_{\mathrm{L}}$ or $\mathrm{WT}_{\mathrm{S}}$ as templates. The two separate $\mathrm{PCR}$ products were then used as templates for the final PCR reaction (PCR c) with primer pair 3. This fragment was then AauI/HindIII digested and cloned into respective sites of $\mathrm{WT}_{\mathrm{L}}$ or $\mathrm{WT}_{\mathrm{S}}$ yielding $\mathrm{hCav1.3} \mathrm{L}_{\mathrm{L}} \mathrm{S} 652 \mathrm{~L}\left(\mathrm{~S} 652 \mathrm{~L}_{\mathrm{L}}\right)$ or hCav1.3 $\mathrm{L}_{\mathrm{L}} \mathrm{S} 652 \mathrm{~W}\left(\mathrm{~S} 62 \mathrm{~W}_{\mathrm{L}}\right)$ and hCav1.3 $\mathrm{S} 652 \mathrm{~L}\left(\mathrm{~S} 652 \mathrm{~L}_{\mathrm{S}}\right)$. The following primer pairs were used for SOE PCR of S652L or S652W constructs (purchased from Eurofins MWG Operon, Ebersberg, Germany): primer pair 1, AauI (BrsGI) fwd: 5'-CCAACAAAGTCCTCTTGGCTCTGT TC-3', S652L SOE rev: 5'-GATAATGAAGAGAAAAA GCAGAAGCAACAGCAAAGCGATGGACTTCATGGA GTTTAATAAG -3' or S652W SOE rev: 5'-GATAATG AAGAGAAAAAGCAGAAGCAACAGCCAAGCGATG GACTTCATGGAGTTTAATAAG -3' (314 bp); primer pair 2: S652L SOE fwd: 5'-CTTATTAAACTCCATGAA GTCCATCGCTTTGCTGTTGCTTCTGCTTTTTCTCT TCATTATC-3' or S652W SOE fwd: 5'-CTTATTAA ACTCCATGAAGTCCATCGCTTGGCTGTTGCTTCT GCTTTTTCTCTTCATTATC-3', HindIII rev: 5'-ATAG ATGAAGAACAGCATGGCTATGAGG-3' (2122 bp); primer pair 3: AauI (BrsGI) fwd, HindIII rev (2375 bp).

PCR reaction mix for PCR a, b and c contained $5 \mu \mathrm{l}$ 10x Pfu buffer with $20 \mathrm{mM} \mathrm{MgSO}_{4}$ (Cat\# EP0571;
Thermo Fisher Scientific,Waltham, MA, USA), $2 \mathrm{mM}$ dNTP mix (Cat\# R0241; Thermo Fisher Scientific, Waltham, MA, USA), $2.5 \mu \mathrm{l}$ DMSO, 500 ng DNA template (PCR a and b) or $0.5 \mu \mathrm{l}$ of PCR products a and $b$ (PCR C), $10 \mathrm{pMol} / \mu \mathrm{l}$ forward primer, $10 \mathrm{pMol} / \mu \mathrm{l}$ reverse primer, $0.5 \mu \mathrm{l} \mathrm{Pfu}$ polymerase (native) $(2.5$ units $/ \mu \mathrm{l}$; Cat\# EP0571; Thermo Fisher Scientific, Waltham, MA, USA) and nuclease-free water to a final volume of $50 \mu \mathrm{l}$. Following PCR program was performed: initial denaturation at $95^{\circ} \mathrm{C}$ for $3 \mathrm{~min}$, then 35 cycles of $30 \mathrm{~s}$ denaturation at $95^{\circ} \mathrm{C}, 30 \mathrm{~s}$ annealing at $50^{\circ} \mathrm{C}$, variable extension time at $72{ }^{\circ} \mathrm{C}$ depending on fragment size (for Pfu polymerase: 2 $\mathrm{min} / \mathrm{kb}$ ) followed by a final elongation step of $72{ }^{\circ} \mathrm{C}$ for $7 \mathrm{~min}$. The integrity of all cloned constructs was confirmed by restriction site mapping and sequencing (Eurofins MWG Operon, Ebersberg, Germany).

\section{Cell culture and transfection}

For whole-cell patch-clamp recordings, tsA-201 cells (a human embryonic kidney (HEK)-293 subclone stably expressing SV40 temperature-sensitive T-antigen, ECACC, 96121229) were cultured in Dulbecco's modified Eagle's medium (DMEM; Cat\# D6546; Merck KGaA, Darmstadt, Germany) containing $4500 \mathrm{mg} / \mathrm{l} \mathrm{L}$-glucose, $10 \%$ fetal bovine serum (FBS; Cat\# 10270106; Thermo Fisher Scientific, Waltham, MA, USA), $2 \mathrm{mML}$-glutamine (Cat\# 25030032; Thermo Fisher Scientific, Waltham, MA, USA), 10 units/ml penicillin G (Cat\# P-3032; Merck KGaA, Darmstadt, Germany), $10 \mu \mathrm{g} / \mathrm{ml}$ streptomycin (Cat\# S-6501; Merck KGaA, Darmstadt, Germany) and maintained at $37{ }^{\circ} \mathrm{C}$ in a humidified incubator with $5 \%$ $\mathrm{CO}_{2}$. Cells were grown to $\sim 80 \%$ confluency and split using $0.05 \%$ trypsin for cell dissociation. Cells were transiently transfected using the $\mathrm{Ca}^{2+}$-phosphate precipitation method always including EGFP $(1.5 \mu \mathrm{g})$ as a transfection marker. For recordings of $\mathrm{WT}_{\mathrm{L}}$ vs $\mathrm{S}_{652} \mathrm{~L}_{\mathrm{L}}$ or $\mathrm{S} 52 \mathrm{~W}_{\mathrm{L}}$ tsA-201 cells were transiently transfected with human $a_{1}(3 \mu \mathrm{g})$, rat $\beta_{3}(2 \mu \mathrm{g}$; Genbank accession number NM_012828), and rabbit $a_{2} \delta-1(2.5 \mu \mathrm{g}$, Genbank accession number NM_001082276) subunits whereas for recordings of $\mathrm{WT}_{\mathrm{S}}$ vs $\mathrm{S} 652 \mathrm{~L}_{\mathrm{S}}$ HEK-293 cells stably expressing $\beta_{3}$ and $a_{2} \delta-1$ were used and required only LTCC $a_{1}(3 \mu \mathrm{g})$ transient transfection [26, 28, 29]. HEK293 cells stably expressing $\beta_{3}$ and $a_{2} \delta-1$ were periodically treated with selection agents for each subunit $\left(\beta_{3}\right.$, $500 \mu \mathrm{g} / \mathrm{ml}$ geneticin (Cat\# 10131027; Thermo Fisher Scientific, Waltham, MA, USA); $a_{2} \delta-1,10 \mu \mathrm{g} / \mathrm{ml}$ blasticidin S HCl (Cat\# A1113903; Thermo Fisher Scientific, Waltham, MA, USA)). All data were obtained from $>3$ independent transfections. On the following day, cells were trypsinized $(0.05 \%$ trypsin) and plated onto poly-L-lysine-(Cat\# P-2636; Merck KGaA, Darmstadt, Germany) precoated $35-\mathrm{mm}$ culture dishes. Cells were kept at 
$30{ }^{\circ} \mathrm{C}$ and $5 \% \mathrm{CO}_{2}$ and were subjected to electrophysiological experiments $20-72 \mathrm{~h}$ after transfection.

\section{Electrophysiological recordings in tsA-201 cells}

For whole-cell patch-clamp experiments, patch pipettes were pulled in a micropipette puller (Sutter Instrument, Novato, CA, USA) using borosilicate glass capillaries (borosilicate glass; Cat\# 64-0792, Warner Instruments, Hamden, CT, USA) and fire-polished using a MF-830 microforge (Narishige Co, Tokyo, Japan). Pipettes with a resistance of 1.5-3 $\mathrm{M} \Omega$ were backfilled with internal solution containing (in $\mathrm{mM}$ ): $135 \mathrm{CsCl}, 10 \mathrm{Cs}$-EGTA, 1 $\mathrm{MgCl}_{2}, 10$ HEPES, $4 \mathrm{Na}_{2}$ ATP adjusted to pH 7.4 with $\mathrm{CsOH}$. The bath solution contained (in $\mathrm{mM}$ ): $15 \mathrm{CaCl}_{2}$ or $15 \mathrm{BaCl}_{2}, 150$ Choline-Cl, $1 \mathrm{MgCl}_{2}, 10$ HEPES, adjusted to $\mathrm{pH} 7.3$ with $\mathrm{CsOH}$. Whole-cell patch-clamp recordings were performed at room temperature (20$23^{\circ} \mathrm{C}$ ) using an Axopatch 200B Amplifier (Molecular Devices, San José, CA, USA). Data were digitized (Digidata, 1322A digitizer, Molecular Devices, San José, CA, USA) at $50 \mathrm{kHz}$, low-pass filtered at $1-5 \mathrm{kHz}$ and analyzed using pClamp 10.2 software (Molecular Devices, San José, CA, USA). Series resistance was compensated by $60-90 \%$ and all voltages were corrected for a liquid junction potential of $-9.3 \mathrm{mV}$ [28]. Currents were leak subtracted either offline using a 50-ms hyperpolarizing voltage step from -89 to $-99 \mathrm{mV}$ or using an online $\mathrm{P} /$ 4 protocol. Current-voltage $(I-V)$ relationships were measured by applying $50 \mathrm{~ms}$ depolarizing square pulses to various test potentials ( $\Delta 5 \mathrm{mV}$ increments) starting from a holding potential (HP) of $-89 \mathrm{mV}$. $I-V$ curves were fitted to the equation $I=\mathrm{G}_{\max }\left(V-V_{\text {rev }}\right) /(1+\exp$ $\left.\left[-\left(V-V_{0.5}\right) / \mathrm{k}\right]\right)$ where $I$ is the peak current, $G_{\max }$ is the maximum conductance, $V$ is the test potential, $V_{\mathrm{rev}}$ is the extrapolated reversal potential, $V_{0.5}$ is the halfmaximal activation voltage, and $\mathrm{k}$ is the slope factor. The voltage dependence of activation was obtained from the $I-V$ relationship by calculating the conductance $(G=$ $\left.I / V-V_{\text {rev }}\right)$ followed by normalization $\left(G / G_{\max }\right)$ and plotting as a function of voltage. The G-V curve was fitted using the following Boltzmann relationship: $G=G_{\max } /(1$ $+\exp \left[-\left(V-V_{0.5}\right) / k\right]$. The steady-state inactivation was determined by calculating the ratio between current amplitudes of a control versus a test pulse $\left(\mathrm{I} / \mathrm{I}_{\text {control }}\right.$; both $20 \mathrm{~ms}$ to $\left.V_{\max }\right)$ separated by a 5 -s conditioning step to various potentials $(10 \mathrm{mV}$ increments; $30 \mathrm{~s}$ intersweep interval; HP: $-89 \mathrm{mV}$ ) and plotting as a function of voltage. Steady-state inactivation curves were fitted using a modified Boltzmann equation: $G=\left(1-G_{\max }\right) /(1+\exp$ $\left[\left(V-V_{0.5 \text {,inact }}\right) / k_{\text {inact }}\right]+G_{\max }$ where $V_{0.5 \text { inact }}$ is the halfmaximal inactivation voltage and $k_{\text {inact }}$ is the inactivation slope factor. Channel open probability was estimated by dividing the peak ionic tail current $\left(I_{\text {tail }}\right)$ by the integrated "ON" gating charge ( $\left.\mathrm{Q}_{\mathrm{ON}}\right)$ at the potential where there is no ionic inward or outward current $\left(V_{\text {rev }}\right)$. ONgating currents were filtered at $5 \mathrm{kHz}$ and digitized at 50 $\mathrm{kHz}$. Window currents were obtained by multiplying the steady-state inactivation at a given voltage (Fig. 1c,d, Fig. $6 \mathrm{~b})$ with the corresponding current densities $(\mathrm{pA} / \mathrm{pF})$ at the given potentials of the $I-V$ relationships (Fig. 1a,b, Fig. 6a). Pulses to physiologically relevant potentials i.e. $-20 \mathrm{mV}$ which corresponds to $\sim-35-38 \mathrm{mV}$ in physiological $\mathrm{Ca}^{2+}$-concentrations were applied for 5-s. Normalized inward $\mathrm{Ca}^{2+}$-currents $\left(I_{\mathrm{Ca}}\right)$ were multiplied with the corresponding conductance at $-20 \mathrm{mV}\left(\mathrm{G}: \mathrm{WT}_{\mathrm{L}}\right.$, 0.1253; S652L $\mathrm{L}_{\mathrm{S}}, 0.4330 ; \mathrm{WT}_{\mathrm{S}}, 0.2647 ; \mathrm{S} 652 \mathrm{~L}_{\mathrm{S}}, 0.6325$ ) and plotted as a function of time. The percentage of inactivation during a 5-s long depolarizing pulse from a $\mathrm{HP}$ of $-89 \mathrm{mV}$ to the potential of maximal inward current $\left(V_{\max }\right)$ was determined after 50, 100, 250, 500, 1000 , and $5000 \mathrm{~ms}$ with $\mathrm{Ca}^{2+}$ or $\mathrm{Ba}^{2+}$ as a charge carrier. $\mathrm{Ca}^{2+}$-dependent inactivation (CDI) was determined over a broad voltage range by analyzing the fraction of remaining currents at the end of $250 \mathrm{~ms}$ depolarizations (expressed as fraction of the peak current amplitude, $\left.r_{250}\right)$ to different test potentials $(\Delta 10-\mathrm{mV}$ increments) with $\mathrm{Ca}^{2+}$ or $\mathrm{Ba}^{2+}$ as a charge carrier resulting in typical $\mathrm{U}$-shaped dependence of voltage. The difference between $\mathrm{Ca}^{2+}$ - and $\mathrm{Ba}^{2+}$-curves indicates the strength of $\mathrm{CDI}$ and is defined as parameter $f$ for each voltage step and plotted as a function of voltage. The fractional $\mathrm{Ca}^{2+}$. dependent component of inactivation after $250 \mathrm{~ms}$ was calculated as CDI $=1-r_{\mathrm{Ca}} / r_{\mathrm{Ba}}$, where $r_{\mathrm{Ca}}$ and $r_{\mathrm{Ba}}$ is the fraction of current remaining at a given time point of inactivation, respectively. Persistent currents were determined after 5-s long depolarizations to different potentials expressed as fractional persistent current (\%) normalized to the peak current amplitude measured by a 20-ms pre-pulse to the $V_{\max }$ in the same sweep. Tail currents were obtained from a transition from $+80 \mathrm{mV}$ to $-60 \mathrm{mV}$ or $-40 \mathrm{mV}$ and normalized tail currents were fitted to a bi-exponential equation. In general, experiments with currents $<100 \mathrm{pA}$ and $>1000 \mathrm{pA}$ (range was defined prospectively) were excluded from analysis to avoid errors in the measurements of $V_{0.5 \text {,act }}$, which tends to become more hyperpolarized at larger current amplitudes. For pharmacological experiments, cells were depolarized using a $100-\mathrm{ms}$ square pulse to the $V_{\max }$ of each individual cell $(0.1 \mathrm{~Hz}$; HP: $-89 \mathrm{mV})$. Cells were perfused using an air pressure-driven perfusion system (BPS-8 Valve Control System, ALA Scientific Instruments) with external bath solution $\left(15 \mathrm{mM} \mathrm{Ca}^{2+}\right)$ in the presence or absence of isradipine (Fisher scientific, 50850-70001) with a flow rate of $0.5 \mathrm{ml} / \mathrm{min}$. Isradipine stocks were prepared in DMSO and freshly diluted 1 : 1000 in bath solution to the final concentration prior to the experiment. On each recording day, individual control recordings with bath solution only were performed 
A

C
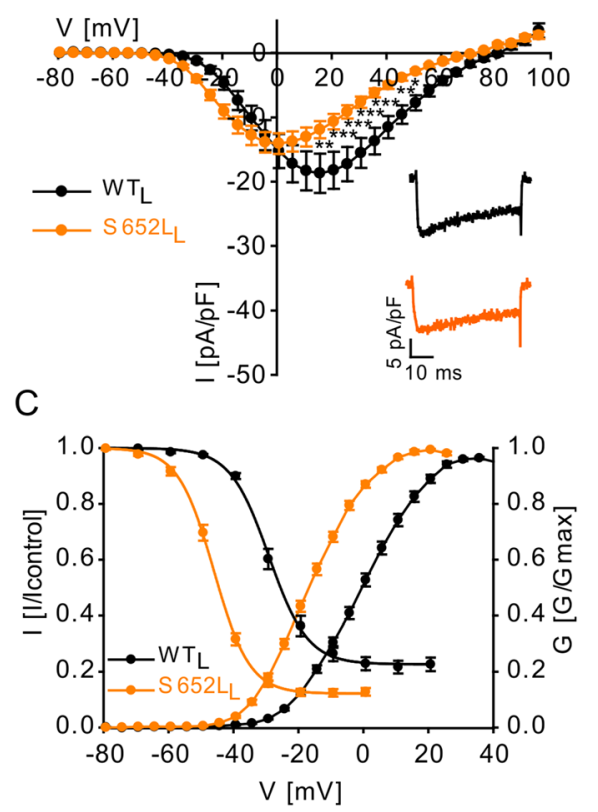

E

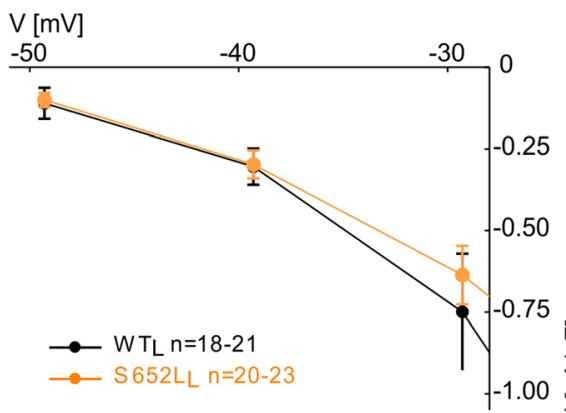

B

D
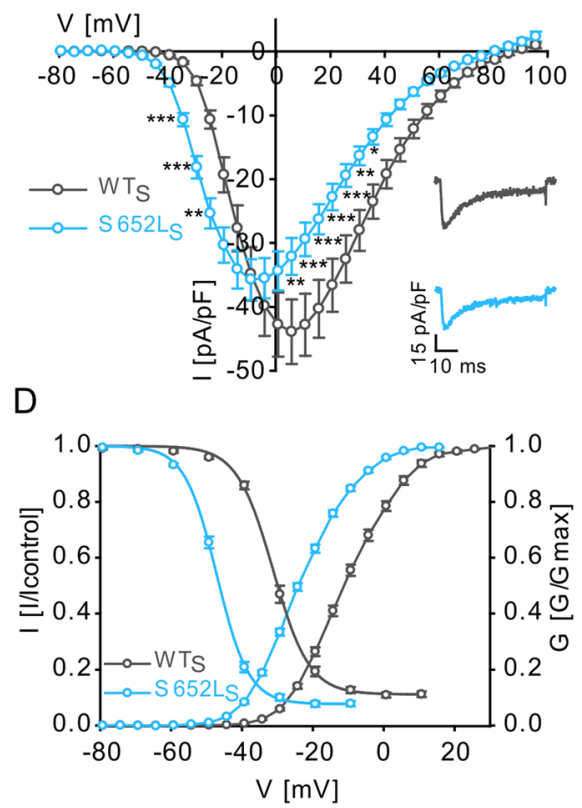

$\mathrm{F}$

$\mathrm{V}[\mathrm{mV}]$

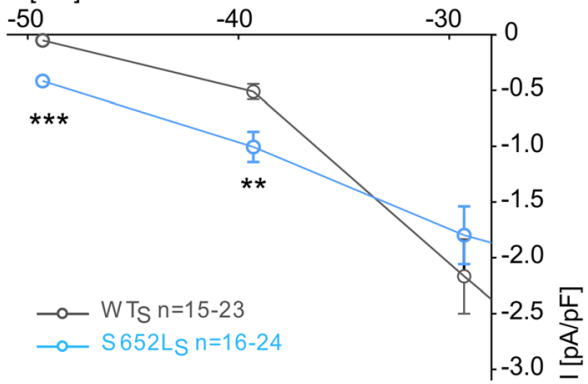

Fig. 1 Mutation S652L induces severe gating changes. a, b Current-voltage relationship (ICai mean \pm SEM) of WT and mutant C-terminal long $\left(\mathrm{WT}_{\mathrm{L}}, \mathrm{S} 652 \mathrm{~L}_{\mathrm{L}}, \mathrm{A}\right)$ and short $\left(\mathrm{WT}_{\mathrm{S}}, \mathrm{S} 652 \mathrm{~L}_{\mathrm{S}}, \mathrm{B}\right)$ Cav1.3 splice variants recorded in parallel on the same day using 50-ms depolarizing square pulses to various test potentials from a holding potential (HP) of $-89 \mathrm{mV}$. Inset: Representative I $_{\text {Ca }}$ traces upon depolarization to the potential of maximal inward current $\left(V_{\text {max }}\right)$. Statistics: two-way ANOVA followed by Bonferroni post hoc test, ${ }^{*} p<0.05,{ }^{* *} p<0.01$, ${ }^{* * *} p<0.001$. c, d Normalized steady-state activation and inactivation curves of $W T_{L}$ vs S652L (c) and $W T_{S}$ vs $5652 L_{S}$ (d). Data are presented as mean \pm SEM; for parameters, statistics and number of experiments see Table 1. e, $\mathbf{f}$ Window currents of $W T_{L} V S S 652 L_{L}(E)$ and $W_{S}$ vs S652L $(F)$. Data were obtained by multiplying the steady-state inactivation (c, d) at a given potential with the corresponding current densities of the I-V-relationships $(\mathbf{a}, \mathbf{b})$. Statistics: Student's t-test (multiple comparison adjusted), ${ }^{* * *} p<0.001,{ }^{* *} p<0.01$. Data are represented as mean \pm SEM for the $n$-numbers indicated. Data were collected from $>3$ independent transfections

using the same tubes subsequently used for isradipine experiments. Drug application was started after at least three constant control sweeps during perfusion with bath solution. Drug effects were corrected for linear current decay ("run-down") measured in control cells.

\section{$\mathrm{Ca}^{2+}$-imaging}

HEK-293 cells stably expressing $\beta_{3}$ and $\alpha_{2} \delta-1$ were transfected with $\mathrm{WT}_{\mathrm{L}}$ or $\mathrm{S} 652 \mathrm{~L}_{\mathrm{L}}$ Cav1.3 $\alpha_{1}$-subunits $(3 \mu \mathrm{g})$ together with EGFP $(1.5 \mu \mathrm{g})$ for visualization of transfected cells. Cells were patched $24-72 \mathrm{~h}$ after transfection at room temperature $\left(21-23^{\circ} \mathrm{C}\right)$ with internal solution containing (in $\mathrm{mM}$ ): $114 \mathrm{CsMeSO}_{3}, 5 \mathrm{CsCl}, 1$ $\mathrm{MgCl}_{2}, 4 \mathrm{Na}_{2} \mathrm{ATP}, 10$ HEPES and 0.5 Cs-EGTA (pH 7.3) and $0.2 \mathrm{mM}$ Fluo-4 pentapotassium salt (cat\#: F14200, Thermo Fisher). During the recording, cells were kept in Tyrode's solution containing (in $\mathrm{mM}$ ): $135 \mathrm{NaCl}, 5.4$ $\mathrm{KCl}, 1.8 \mathrm{CaCl}_{2}, 0.33 \mathrm{MgCl}_{2}, 0.33 \mathrm{NaH}_{2} \mathrm{PO}_{4}, 5$ HEPES and 5 glucose ( $\mathrm{pH}$ 7.4). Fluorescence from transfected cells was detected using Photon Technology International (PTI) photomultipliers and manufacturer's software. Excitation was performed at $488 \mathrm{~nm}$ and fluorescent emission from each sample was recorded at $520 \mathrm{~nm}$. Action potential waveform (APW)-like stimulus 
trains were applied at a frequency of $10 \mathrm{~Hz}$ and 300 sweeps per run. The APW protocol was elicited from 80-mV HP composed of 3 voltage ramps: step: -80 to $60 \mathrm{mV}$ for $2.5 \mathrm{~ms}$, 1st ramp: -60 to $+20 \mathrm{mV}$ in $1 \mathrm{~ms}$, 2nd ramp: +20 to $-70 \mathrm{mV}$ in $1.5 \mathrm{~ms}$, 3rd ramp: -70 to - $60 \mathrm{mV}$ in $5 \mathrm{~ms}$ (afterhyperpolarization), step: $-60 \mathrm{mV}$ for $90 \mathrm{~ms}$. Fluorescent signals were normalized to baseline fluorescence $\left(\mathrm{F}_{0}\right)$ and current density $(\mathrm{pA} / \mathrm{pF})$ determined in a ramp before the start of the train. $\mathrm{Ca}^{2+}$ charge of $\mathrm{WT}_{\mathrm{L}}$ and $\mathrm{S} 62 \mathrm{~L}_{\mathrm{L}}$ was obtained by integrating the area of $I_{\text {tail }}$ normalized to maximum $I_{\mathrm{Ca}}$ determined in a ramp before the start of the train.

\section{Protein preparation and immunoblot analysis of HEK-293 cells}

HEK-293 cells stably expressing $\beta_{3}$ and $a_{2} \delta-1$ were transiently transfected with $\mathrm{WT}_{\mathrm{L} / \mathrm{S}}$ and mutant $\alpha_{1}$-subunits using JetPrime ${ }^{\otimes}$ transfection reagent (VWR International, Radnor, PA, USA) according to the manufacturer's protocol. Membrane preparations were performed $48 \mathrm{~h}$ after transfection by first washing cells with phosphatebuffered saline (in mM: $137 \mathrm{NaCl}, 2.7 \mathrm{KCl}, 8 \mathrm{Na}_{2} \mathrm{HPO}_{4}$, $1.5 \mathrm{KH}_{2} \mathrm{PO}_{4}$ ). Subsequently, cells were harvested and resuspended in $2 \mathrm{ml}$ lysis buffer $(10 \mathrm{mM}$ Tris- $\mathrm{HCl}, 1 \mu \mathrm{g} / \mathrm{ml}$ aprotinin, $0.1 \mathrm{mg} / \mathrm{ml}$ trypsin inhibitor, $1 \mu \mathrm{M}$ pepstatin A, $0.5 \mathrm{mM}$ benzamidine, $0.2 \mathrm{mM}$ phenylmethylsulfonylfluoride, $2 \mathrm{mM}$ iodacetamide, $1 \mu \mathrm{l} / \mathrm{ml}$ leupeptin, $\mathrm{pH} 7.4$ ) and lysed on ice for $15 \mathrm{~min}$. After resuspension, the mixture was homogenized by passing it through a 27 -gauge cannula and centrifuged for $20 \mathrm{~min}$ at $726 \times g$ to remove cell debris. Membranes were collected by subjecting the resulting supernatant to an ultracentrifugation step at $110,561 \times g$ for $30 \mathrm{~min}$. The pellet was resuspended in $200 \mu \mathrm{l}$ of lysis buffer and stored at $-80^{\circ} \mathrm{C}$. Protein concentrations were measured via Bradford assay. Proteins were mixed with $4 \times \mathrm{NuPAGE}^{\mathrm{TM}}$ LDS sample buffer (Cat\# NP0008; Thermo Fisher Scientific, Waltham, MA, USA) and incubated at $70{ }^{\circ} \mathrm{C}$ for $10 \mathrm{~min}$ before loading onto NuPAGE ${ }^{\mathrm{TM}} 3-8 \%$ Tris-acetate protein gels (Thermo Fisher Scientific, Waltham, MA, USA) together with a PageRuler ${ }^{\mathrm{TM}}$ Plus prestained protein ladder (10$250 \mathrm{kDa}$; Cat\# 26619; Thermo Fisher Scientific, Waltham, MA, USA). Proteins were separated using a $20 \times$ NuPAGE $^{\mathrm{TM}}$ Tris-acetate SDS running buffer (Cat\# LA0041; Thermo Fisher Scientific, Waltham, MA, USA) at $50 \mathrm{~V}$ for $40 \mathrm{~min}$ and $100 \mathrm{~V}$ for $1 \mathrm{~h}$. Proteins were transferred onto a polyvinyliden fluoride membrane (PVDF, Immobilon-P membrane, Cat\# IPVH00010; Merck KGaA, Darmstadt, Germany) in transfer buffer (20x NuPAGE ${ }^{\mathrm{TM}}$ Tris-acetate SDS running buffer, 20\% Methanol $(\mathrm{v} / \mathrm{v}))$ at $100 \mathrm{~V}$ for $90 \mathrm{~min}$. After the transfer, the membrane was blocked for $2 \mathrm{~h}$ at room temperature in blocking buffer ( $5 \%$ milk powder and $0.2 \%$ gelatine in $20 \mathrm{mM}$ Tris, $150 \mathrm{mM} \mathrm{NaCl}, 0.5 \%$ Triton X-100, $0.1 \%$
Tween 20) and incubated with the primary antibody in blocking buffer at $4{ }^{\circ} \mathrm{C}$ overnight. $\alpha_{1}$-subunits were detected using anti-Cav1.3 antibody (rabbit-polyclonal; Cat\# ACC-005, Lot\# AN2150; Alomone labs, Jerusalem, Israel; diluted 1:100,000). Anti-a-tubulin (mouse-monoclonal (DM1A); Cat\# CP06, Lot\# D00143511; Merck KGaA, Darmstadt, Germany; diluted 1:100,000) was used as loading control. After washing with washing buffer (20 mM Tris, $150 \mathrm{mM} \mathrm{NaCl}, 0.5 \%$ Triton X-100, 0.1\% Tween 20) the membrane was incubated with the secondary antibody in blocking buffer for $2 \mathrm{~h}$ at room temperature followed by another wash step. Peroxidase conjugated goat anti-rabbit IgG (whole molecule; Cat\# A0545, Lot\# SLBC3108; Merck KGaA, Darmstadt, Germany; diluted 1:15,000) and peroxidase conjugated goat anti-mouse IgG (H+L; Cat\# 31430, Lot\# SC245915; Thermo Fisher Scientific, Waltham, MA, USA; diluted 1: 5000) were used as secondary antibodies. For detection, the SuperSignal ${ }^{\mathrm{TM}}$ West Femto maximum sensitivity substrate (Cat\# 34096; Thermo Fisher Scientific, Waltham, MA, USA) was used. Signals were quantified with a FUSION FX7 Imager (Vilber Lourmat Deutschland $\mathrm{GmbH}$, Eberhardzell, Germany) and analysis of band intensity using ImageJ 1.46 (National Institute of Health). Integrated densities of mutant and WT signals were normalized to the loading control.

The absolute expression level of $\alpha_{1}$-subunit protein varies between membrane preparations of individual transfections. Therefore, transfections, membrane preparations, and Western blot analysis were always carried out in parallel for WT and mutant channels.

\section{Homology modeling}

We predicted the structure of the WT Cav1.3 $\alpha_{1}$-subunit and two mutants by developing a homology model based on the cryo-electron microscopy (EM) structure of the Cav1.1 $\alpha_{1}$-subunit in the closed (potentially inactivated) state [30]. The high sequence conservation of the Cav1.1 $\alpha_{1}$-subunit to the Cav1.3 $\alpha_{1}$-subunit ( 75\% similarity and $\sim 62 \%$ identity measured by MOE) allowed us to predict a reliable structure model.

Homology modeling has been performed using Rosetta and MOE (Molecular Operating Environment, version 2018.08, Molecular Computing Group Inc., Montreal, Canada). Additionally, ab initio Rosetta was used to generate structures for loops that were not resolved in the original Cav1.1 $\alpha_{1}$-subunit template. The structures for the mutants were derived from the WT model by replacing the mutated residue and carrying out a local energy minimization using MOE. The C-terminal and $\mathrm{N}$ terminal parts of each domain were capped with acetylamide (ACE) and N-methylamide to avoid perturbations by free charged functional groups. The structure model was embedded in a plasma membrane consisting of 
POPC (1-palmitoyl-2-oleoyl-sn-glycero-3-phosphocholine) and cholesterol in a 3:1 ratio, using the CHARMMGUI Membrane Builder. Water molecules and $0.15 \mathrm{M}$ $\mathrm{KCl}$ were included in the simulation box. Energy minimizations of WT and mutant structures in the membrane environment were performed. The topology was generated with the LEaP tool of the AmberTools18, using force fields for proteins and lipids, ff14SBonlysc and Lipid14, respectively. The WT and mutant structures were gradually heated from 0 to $300 \mathrm{~K}$ in two steps, keeping the lipids fixed, and then equilibrated over $1 \mathrm{~ns}$. Then molecular dynamics simulations were performed for $10 \mathrm{~ns}$, with time steps of $2 \mathrm{fs}$, at $300 \mathrm{~K}$ and in anisotropic pressure scaling conditions. Van der Waals and short-range electrostatic interactions were cut off at $10 \AA$, whereas long-range electrostatics were calculated by the Particle Mesh Ewald (PME) method. MOE was used to visualize the key interactions and point out differences in the WT and mutant structures.

\section{Ethics approval}

The Deciphering Developmental Disorders Study [23] has UK Research Ethics Committee approval (10/ H0305/83, granted by the Cambridge South REC, and GEN/284/12 granted by the Republic of Ireland REC). Parental informed consent has been obtained for updated clinical information of the probands.

\section{Statistics}

Data were analyzed using Clampfit 10.2 (Axon Instruments) and Sigma Plot 11 (Systat Software, Chicago, IL). For statistical analysis Graph Pad Prism 5.01 software (GraphPad Software, La Jolla, CA) was used. Significance of group differences between two groups was determined using unpaired Student's $t$ test for normally distributed data or Mann-Whitney $U$ test for non-normally distributed data. Significance of group differences between three and more groups was determined using one-way analyses of variance (ANOVA) or two-way ANOVA for normally distributed data (with Bonferroni post-test as indicated). All data are represented as mean \pm SEM. Significance level was set to $\alpha$-error lower than $p<0.05{ }^{(*)}, p<0.01{ }^{(* *)}$ and $p<0.001{ }^{(* * *)}$. All original datasets are available from the corresponding author on reasonable request.

\section{Results}

$S 652 L$, a novel CACNA1D de novo mutation in monozygotic twins with a severe neurodevelopmental disorder and ASD

The novel CACNA1D variant has been reported in the Deciphering Developmental Disorders Study [23]. In a large unbiased genotype-driven approach this study analyzed 1,133 children with severe, undiagnosed developmental disorders and their parents using a combination of exome sequencing and array-based detection of chromosomal rearrangements [23]. The CACNA1D variant (chr3: $53757881 \mathrm{C}>\mathrm{T}$, human reference genome hg19) was predicted to cause a p.Ser652Leu (S652L) mutation (reference sequence NM_001128839). However, it was not considered a novel disease mutation in this study. The patients (DECIPHER database individuals \#262954 and \#262956; decipher.sanger.ac.uk) are male monozygotic twins, thirteen years old at present, and both harbor one copy of the mutation. Their clinical phenotype has been updated recently. It manifests as a severe neurodevelopmental phenotype with delayed speech and language development and a global developmental delay. Both individuals show self-injurious behaviors and have been diagnosed with ASD two years ago. One patient is tall ( $5 \mathrm{ft} 5 \mathrm{in}$.) and heavy $(57 \mathrm{~kg})$ for his age, has undescended testes and suffered from seizures at the age of two without recurrence. In addition, he shows challenging behavior with attention deficit hyperactivity disorder-like symptoms. No abnormal blood pressure has so far been reported and both are currently not treated with any medication. In addition, facial dysmorphism characterized by epicanthus, abnormality of the nose, microtia, a small vermillion border, and widely spaced teeth was noted. Prediction of the possible impact of this amino acid substitution on protein structure and function using bioinformatics prediction tools PolyPhen2, SIFT and MutationTaster indicated a probably damaging (score: 1.00$)$, deleterious $(100 \%)$ or diseasecausing (probability: 0.999) effect, respectively. This variant is not reported in the gnomAD database (a reference database that lists exomes and genomes from a total of 141,456 unrelated individuals harboring mutations without pediatric disease [21]).

A frameshift mutation (c.1934_1935insG (p.Glu646GlyfsTer)) in the KIF22 gene (chr16: 29816479 T>TG, human reference genome hg19) was also identified in both patients. This gene is highly expressed in bones, cartilage, skin, ligaments and joint capsules [31]. Mutations in the KIF22 gene have so far not been associated with neurodevelopmental disorders but result in a syndrome called spondyloepimetaphyseal dysplasia with joint laxity (SEMDJL; OMIM \#603213), with malformations of the spine, skeletal dysplasia and malalignment of limbs but no intellectual impairment. Complete knock-out of Kif22 in mice results in premature intrauterine death but surviving $\mathrm{Kif}_{22^{-/-}} \mathrm{em}-$ bryos develop into healthy adult mice [32]. Moreover, protein loss-of-function variants (stop gained, frameshift mutations) are reported in more than 40 controls in the gnomAD database. Therefore, the KIF22 mutation is unlikely to explain the severe neurodevelopmental phenotype of the two patients. In contrast, 
CACNA1D mutation S652L has also been reported as a somatic aldosterone-producing-adenoma (APA) mutation [33] in a patient suffering from resistant hypertension, providing additional indirect evidence for a pathogenic role of this novel germline CACNA1D variant.

\section{Mutation S652L changes the voltage-dependence of activation and inactivation}

Based on recent findings of unique gating changes induced by pathogenic CACNA1D de novo mutations [14$18,20,34]$, we therefore hypothesized that $S 652 \mathrm{~L}$ could also explain the neurodevelopmental phenotype in both patients. For a detailed biophysical characterization in tsA-201 cells we introduced this mutation into the biophysically distinct C-terminally long $\left(\mathrm{WT}_{\mathrm{L}}, \mathrm{S} 652 \mathrm{~L}_{\mathrm{L}}\right)$ and short $\left(\mathrm{WT}_{\mathrm{S}}, \mathrm{S} 652 \mathrm{~L}_{\mathrm{S}}\right)$ Cav1.3 splice variants [26]. Both splice variants are abundantly expressed in the brain and differ considerably with respect to their biophysical properties, with higher voltage-sensitivity and faster $\mathrm{Ca}^{2+}$ dependent inactivation of $\mathrm{WT}_{\mathrm{S}}[3,16]$. Mutant $\alpha_{1}$-subunit proteins were expressed as intact proteins with the expected molecular mass (Additional file 1: Figure S1).

Mutation S652L induced pronounced gating changes. It significantly shifted the voltage-dependence of activation (Fig. 1a, b) and steady-state inactivation to more negative potentials indicating a phenotype that can support a channel gain-of-function in both splice variants (Fig. 1c, d; for parameters see Table 1) by promoting $\mathrm{Ca}^{2+}$-inward currents $\left(\mathrm{I}_{\mathrm{Ca}}\right)$ at negative voltages. As a consequence the mutation induced a higher window current at subthreshold potentials $(-50$ and $-40 \mathrm{mV}$ ) compared to WT in the short Cav1.3 splice variant (Fig. 1e, f). These variants comprise about half of the Cav1.3 $\alpha_{1}$-subunits in the brain [35]. At $-50 \mathrm{mV}$ significant window current was only measurable in $\mathrm{S} 652 \mathrm{~L}_{\mathrm{S}}$ but not in $\mathrm{WT}_{\mathrm{S}}$, and it was two times larger in the mutant at $-40 \mathrm{mV}$. Whereas current amplitudes were larger at negative voltages, $I_{\mathrm{Ca}}$ above the potential of maximal inward current $\left(V_{\max }\right)$ were significantly smaller (Fig. 1a, b). Since gating currents, which are a measure for the number of active channels at the cell surface, were not different in the mutant channels (QON [mean \pm SEM; pA*ms)]: $\mathrm{WT}_{\mathrm{L}}, 158.9 \pm 26.3, n=23$; S652 $\mathrm{L}_{\mathrm{L}}, 140.3 \pm 25.1, n=21$; Mann-Whitney test), reduced current density is likely due to a decreased open probability $\left(\mathrm{P}_{\mathrm{O}}\right)$. This is further supported by a significantly decreased slope of the $I_{\text {tail }} / \mathrm{Q}_{\mathrm{ON}}$ relationship for $\mathrm{S} 652 \mathrm{~L}_{\mathrm{L}}$ channels $\left(I_{\text {tail }} / Q_{\text {ON }}\right.$ linear regression slopes, mean $\pm \mathrm{SEM}$; $\mathrm{ms}^{-1}$ ]: $\mathrm{WT}_{\mathrm{L}}:-7.22 \pm 0.916, r^{2}=0.72, n=26 ; \mathrm{S}^{2} 52 \mathrm{~L}_{\mathrm{L}}:-$ $4.24 \pm 0.657, r^{2}=0.72, n=25$; slopes are significantly different: $F=6.43, p=0.015, F$ test; Additional file 2: Figure S2).

Note that short Cav1.3 splice variants have very small, non-measurable ON-gating currents [26] and were therefore not further analyzed here.

\section{Mutation S652L accelerates voltage-dependent inactivation but has opposing effects on $\mathrm{Ca}^{2+}$-dependent inactivation}

Since either acceleration or slowing of the inactivation time course of Cav1.3 is also a hallmark of pathogenic CACNA1D mutations, we studied voltage(VDI) and $\mathrm{Ca}^{2+}$-dependent inactivation (CDI). Mutation S652L significantly accelerated inactivation kinetics (Fig. 2) during 5-s depolarizations to $V_{\max }$ with both $\mathrm{Ba}^{2+}$ (which reports VDI) and $\mathrm{Ca}^{2+}$ (which, in addition, induces CDI) as charge carriers in both Cterminally long (Fig. 2a) and short (Fig. 2b; for statistics, see Table 2) splice variants. It also significantly reduced $I_{\mathrm{Ca}}$ during long-lasting depolarizations as shown as the percentage of remaining current after 5$\mathrm{s}$ depolarizations to various test potentials in both Cav1.3 splice variants (Fig. 2c, d). By comparing the difference of fractional inactivation between $\mathrm{I}_{\mathrm{Ca}}$ and inward $\mathrm{Ba}^{2+}$-current $\left(I_{\mathrm{Ba}}\right)$ after $250-\mathrm{ms}$ depolarizations to different test potentials ( $f$ value, see Fig. 3) mutational effects on the voltage-dependence of CDI could also be determined. Whereas maximal CDI was unchanged in the long Cav1.3 splice variant (Fig. 3a, c), it was significantly reduced in the short variant (Fig. $3 b, d)$. Therefore, faster inactivation of $\mathrm{I}_{\mathrm{Ca}}$ must be due to the acceleration of VDI, despite being partially

Table 1 Steady-state activation and inactivation parameters of mutation S652L

\begin{tabular}{|c|c|c|c|c|c|c|c|c|}
\hline \multirow[b]{2}{*}{$a_{1}$-subunit } & \multicolumn{4}{|l|}{ Activation } & \multicolumn{4}{|l|}{ Inactivation } \\
\hline & $V_{0.5}(\mathrm{mV})$ & $k(m V)$ & $V_{\text {rev }}(\mathrm{mV})$ & $n$ & $V_{0.5, \text { inact }}(\mathrm{mV})$ & $k(m V)$ & Non-inactivating (\%) & $n$ \\
\hline$\overline{W T_{L}}$ & $-0.18 \pm 0.97$ & $9.63 \pm 0.19$ & $71.1 \pm 1.46$ & 21 & $-25.7 \pm 1.42$ & $5.64 \pm 0.26$ & $22.5 \pm 2.26$ & 18 \\
\hline $\mathrm{S} 652 \mathrm{~L}_{\mathrm{L}}$ & $-16.3 \pm 0.75^{* * *}$ & $8.27 \pm 0.10^{* * *}$ & $59.9 \pm 1.03^{* * *}$ & 23 & $-43.3 \pm 1.29^{* * *}$ & $4.99 \pm 0.12^{*}$ & $12.8 \pm 1.31^{* * *}$ & 20 \\
\hline $\mathrm{WT}_{\mathrm{S}}$ & $-10.6 \pm 0.72$ & $7.65 \pm 0.13$ & $64.7 \pm 0.71$ & 23 & $-31.2 \pm 0.67$ & $4.78 \pm 0.23$ & $12.1 \pm 0.99$ & 15 \\
\hline $\mathrm{S} 652 \mathrm{~L}_{\mathrm{S}}$ & $-23.5 \pm 0.44^{* * *}$ & $7.32 \pm 0.10^{*}$ & $58.4 \pm 0.54^{* * *}$ & 24 & $-47.2 \pm 0.42^{* * *}$ & $4.24 \pm 0.16$ & $9.14 \pm 0.96^{*}$ & 15 \\
\hline
\end{tabular}

Parameters were obtained from fitting normalized steady-state activation (G/Gmax) or inactivation curves (I//max) to a Boltzman relationship. All values are presented as mean \pm SEM ( $>3$ independent transfections). Statistics: unpaired Student's $t$ test, ${ }^{*} p<0.05,{ }^{* * *} p<0.001$ compared to WT. $n$, number of recordings. $V_{0.5}$, half maximal activation/inactivation voltage; $V_{\text {rev }}$, reversal potential; $W T$, wild-type 


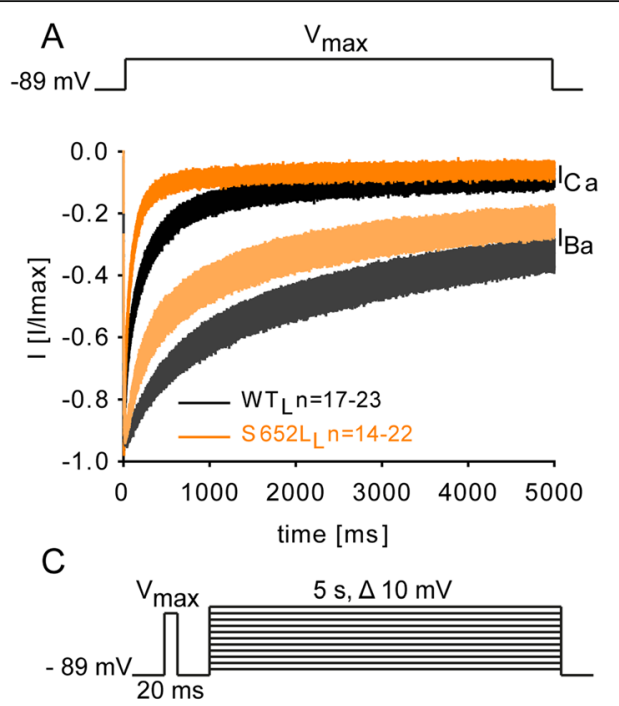

\section{B \\ B}

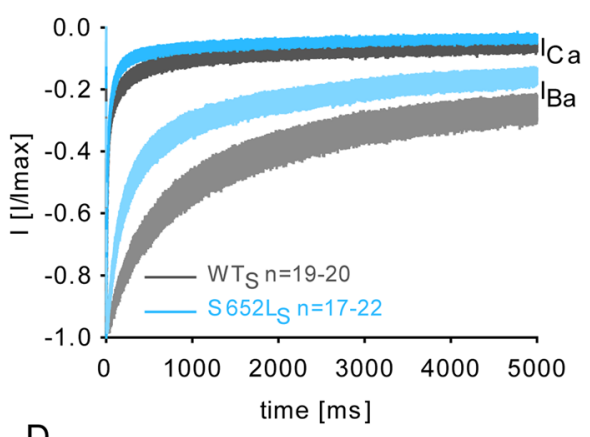

$\mathrm{D}$
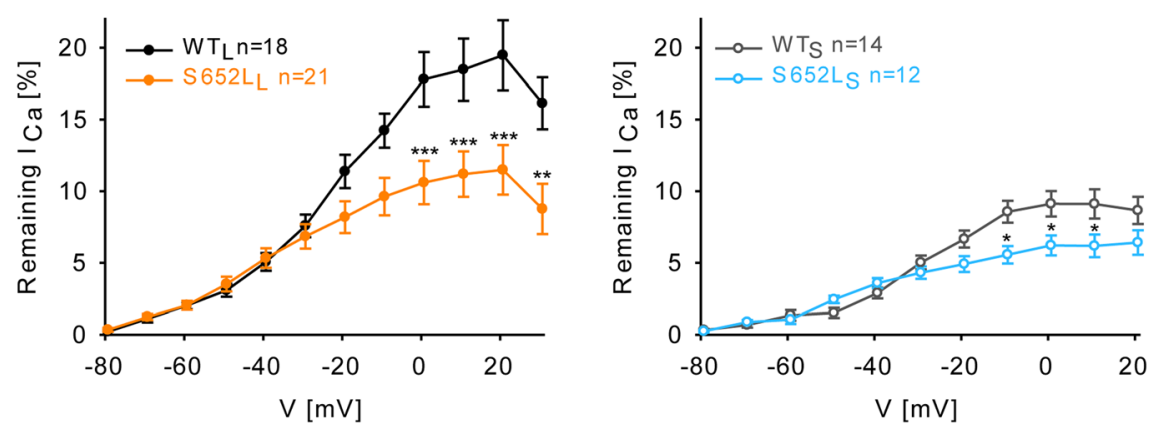

Fig. 2 Mutation S652L accelerates voltage-dependent inactivation and reduces persistent currents. (a, b) Inactivation kinetics of $W T_{L} V S S 652 L_{L}(A)$ and $\mathrm{WT}_{\mathrm{S}}$ vs S652 $\mathrm{L}_{S}$ (B) during a prolonged (5-S) depolarization to $V_{\max }$ with $\mathrm{Ca}^{2+}$ (CDI and VDI) or Ba ${ }^{2+}$ (VDI only; dim colors) as a charge carrier. Data are presented as mean \pm SEM for the $n$-numbers indicated; for statistics see Table 2. c, d Persistent currents were determined after 5-s long depolarizations to different potentials and are expressed as \% of the peak current amplitude measured by a preceding $20 \mathrm{~ms}$ pre-pulse to $V_{\max }$. Statistics: two-way ANOVA followed by Bonferroni post hoc test, ${ }^{*} p<0.05,{ }^{* * *} p<0.001$. Data are represented as mean \pm SEM for the $n$-numbers indicated.

Table 2 Normalized inactivation kinetic parameters of mutation S652L

\begin{tabular}{|c|c|c|c|c|c|c|c|}
\hline$a_{1}$-subunit & $r_{50}$ & $r_{100}$ & $r_{250}$ & $r_{500}$ & $r_{1000}$ & $r_{5000}$ & $n$ \\
\hline \multicolumn{8}{|c|}{ Remaining $\mathrm{I}_{\mathrm{Ca}}[\%]$} \\
\hline$W T_{L}$ & $65.6 \pm 2.66$ & $54.5 \pm 2.96$ & $36.9 \pm 2.96$ & $24.9 \pm 2.65$ & $16.9 \pm 2.40$ & $8.60 \pm 2.20$ & 23 \\
\hline $\mathrm{S} 652 \mathrm{~L}_{\mathrm{L}}$ & $52.8 \pm 2.05^{* * *}$ & $35.2 \pm 1.92^{* * *}$ & $17.1 \pm 1.68^{* * *}$ & $10.8 \pm 1.52^{* * *}$ & $8.04 \pm 1.43^{* *}$ & $5.33 \pm 1.33$ & 22 \\
\hline$W T_{S}$ & $29.3 \pm 2.07$ & $23.3 \pm 1.90$ & $17.1 \pm 1.71$ & $12.9 \pm 1.45$ & $10.1 \pm 1.10$ & $6.21 \pm 0.81$ & 20 \\
\hline$S 652 L_{S}$ & $26.4 \pm 1.47$ & $17.6 \pm 1.25^{*}$ & $10.5 \pm 0.99^{* *}$ & $7.11 \pm 1.05^{* *}$ & $6.15 \pm 0.63^{* *}$ & $3.34 \pm 0.40^{* *}$ & 22 \\
\hline \multicolumn{8}{|c|}{ Remaining $\mathrm{I}_{\mathrm{Ba}}[\%]$} \\
\hline$W T_{L}$ & $92.55 \pm 0.77$ & $88.74 \pm 1.02$ & $79.10 \pm 1.77$ & $68.4 \pm 2.75$ & $57.37 \pm 3.36$ & $30.26 \pm 3.30$ & 17 \\
\hline $\mathrm{S} 652 \mathrm{~L}_{\mathrm{L}}$ & $86.78 \pm 0.92^{* * *}$ & $76.91 \pm 1.70^{* * *}$ & $59.05 \pm 2.42^{* * *}$ & $47.17 \pm 2.94^{* * * *}$ & $36.33 \pm 3.12^{* * * *}$ & $17.24 \pm 2.70^{* *}$ & 14 \\
\hline $\mathrm{WT}_{\mathrm{S}}$ & $93.57 \pm 0.88$ & $88.24 \pm 1.46$ & $76.96 \pm 2.83$ & $64.48 \pm 3.64$ & $50.89 \pm 4.26$ & $25.67 \pm 3.49$ & 19 \\
\hline $\mathrm{S} 652 \mathrm{~L}_{\mathrm{S}}$ & $84.74 \pm 1.66^{* * *}$ & $72.67 \pm 2.70^{* * *}$ & $53.91 \pm 3.35^{* * *}$ & $40.74 \pm 3.35^{* * * *}$ & $29.98 \pm 2.76^{* * *}$ & $15.27 \pm 1.92^{*}$ & 17 \\
\hline
\end{tabular}

$r$ values represent the percent of remaining $I_{\mathrm{Ca}}$ or $I_{\mathrm{Ba}}$ after $50,100,250,500,1000$ and $5000 \mathrm{~ms}\left(5\right.$-s depolarization from a HP of $-89 \mathrm{mV}$ to $V_{\text {max }}$ ). All values are presented as mean \pm SEM ( $>3$ independent transfections). Statistics: unpaired Student's $t$ test of $r$ values, ${ }^{*} p<0.05$, ${ }^{* *} p<0.01,{ }^{* * *} p<0.001$ in comparison to respective WT. $n$, number of recordings; $W T$, wild-type 

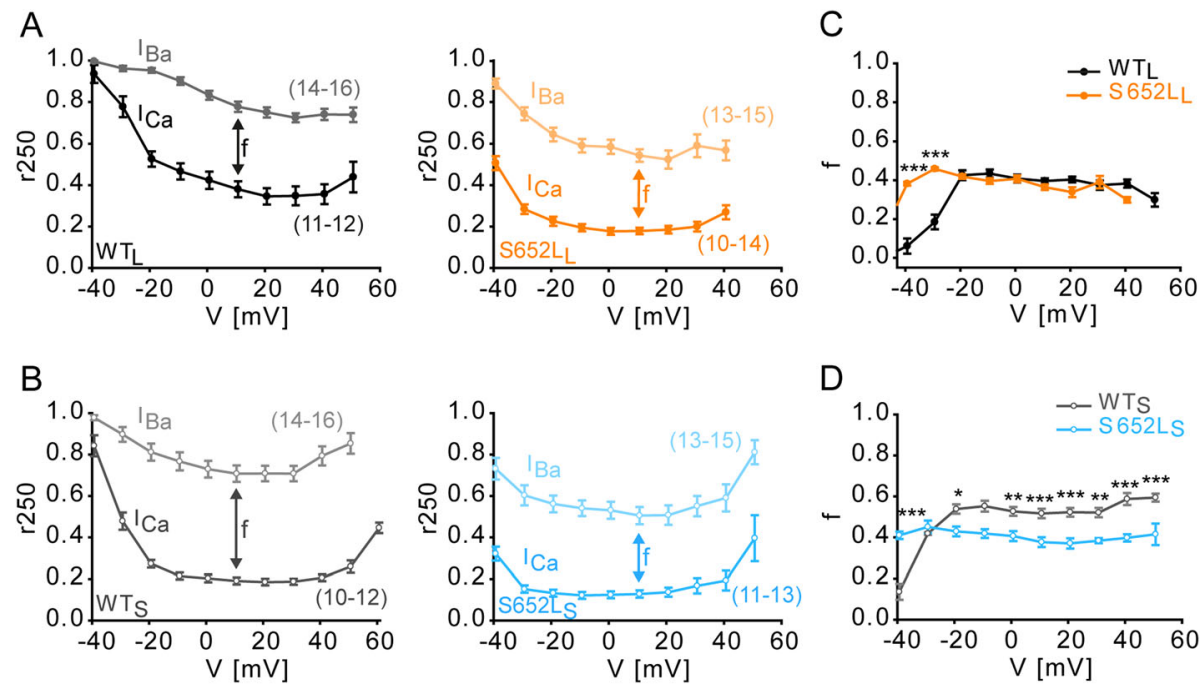

Fig. 3 Mutation S652 $\mathrm{L}$ alters $\mathrm{Ca}^{2+}$-dependent inactivation over a broad voltage range. $\mathbf{a}$, $\mathbf{b}$ Voltage-dependence of $\mathrm{Ca}^{2+}$-dependent inactivation of $\mathrm{WT}_{\mathrm{L}}$

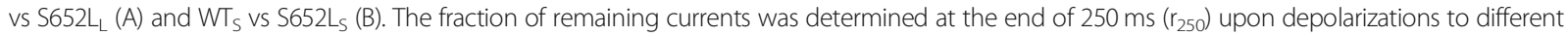
test potentials resulting in a typical U-shaped dependence of voltage. Data are presented as mean \pm SEM (> 3 independent transfections); $n$-numbers are given in parenthesis. $\mathbf{c}, \mathbf{d} f$ values over a broad voltage range for $W T_{L}$ vs $S 652 L_{L}(C)$ and $W T_{S} v s ~ S 652 L_{S}(D) . f$ is defined as the difference between $r_{250}$ values of $I_{B a}$ and $I_{C a}$ at each voltage step and indicates the strength of CDI. CDI of S652 L and S652L was more pronounced at negative potentials. At higher potentials CDI remained unchanged for the long mutant but was significantly reduced for S652Ls. Statistics: two-way ANOVA of $f$ values followed by Bonferroni post hoc test, ${ }^{*} p<0.05,{ }^{* *} p<0.01,{ }^{* * *} p<0.001$ compared to WT. Data are presented as mean \pm SEM $(>3$ independent transfections)

compensated by reduced $\mathrm{CDI}$ in $\mathrm{WT}_{\mathrm{S}}$. Assuming that CDI and VDI are independent processes, we also calculated the fractional $\mathrm{Ca}^{2+}$-dependent component of inactivation as previously described [36] for $\mathrm{WT}_{\mathrm{S}}$ vs $\mathrm{S}_{652} \mathrm{~L}_{\mathrm{S}}$ from the data shown in Table 2. After $250 \mathrm{~ms}$ of inactivation there was no difference between $\mathrm{WT}_{\mathrm{S}}$ $(0.778 \pm 0.027)$ and $\mathrm{S}^{2} 52 \mathrm{~L}_{\mathrm{S}}(0.805 \pm 0.021 ; p=0.40$, $n=21$; unpaired Student's $t$ test) and this was also true for all other time points. This further confirms that S652L can promote Cav1.3 inactivation largely by affecting VDI.

\section{Mutation $\mathrm{S} 652 \mathrm{~L}$ increases $\mathrm{Ca}^{2+}$-signaling during stimulation protocols simulating neuronal firing patterns} In order to predict the consequences of mutation S652L on $\mathrm{Ca}^{2+}$-influx during neuronal activity patterns, we simulated its activity during sustained upstate potentials and during action potential firing.
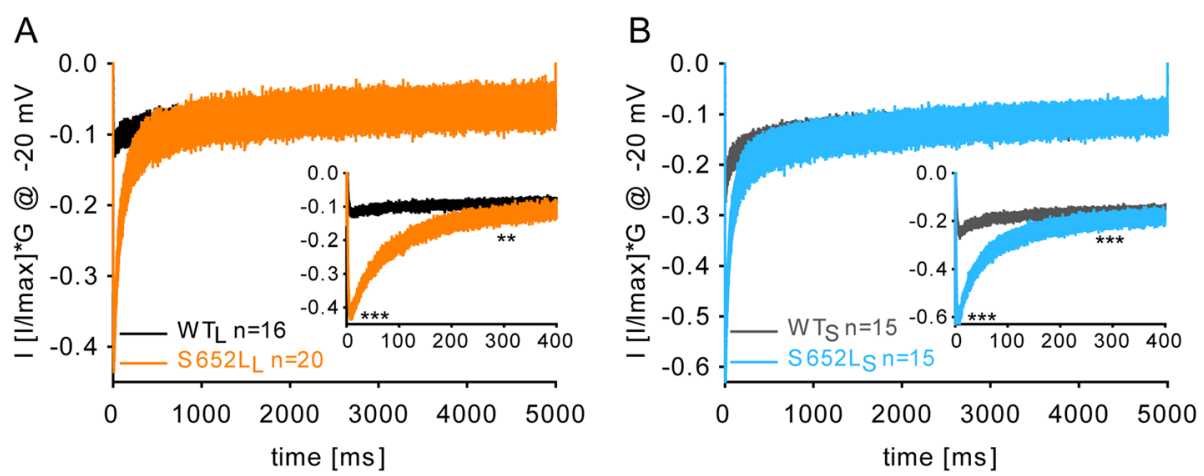

Fig. 4 Mutation S652L increases $\mathrm{Ca}^{2+}$-influx during sustained upstate potentials. a, b Normalized representative $I_{C_{a}}$ of $W T_{L}$ vs S652 $L_{L}(A)$ and $W T_{S}$ vS S652Ls (B) multiplied with the corresponding conductance at a physiologically relevant potential of $-20 \mathrm{mV}$, which corresponds to $\sim-35-38 \mathrm{mV}$ at physiological $\mathrm{Ca}^{2+}$-concentrations $\left(\mathrm{WT}_{\mathrm{L}}, 0.1253 ; \mathrm{S} 652 \mathrm{~L}_{\mathrm{L}}, 0.4330 ; \mathrm{WT}_{\mathrm{S}}, 0.2647 ; \mathrm{S} 652 \mathrm{~L}, 0.6325 ;\right.$ Fig. 1) and plotted as a function of time. Insets show the first $400 \mathrm{~ms}$. Data are presented as mean \pm SEM for the $n$-numbers indicated. Statistics: unpaired Student's $t$ test of $I_{\mathrm{Ca}}$ at peak ([mean $\left.\pm S E M ; \mathrm{PA}^{*} \mathrm{pS}\right]: \mathrm{WT}_{\mathrm{L}}-$ $\left.0.12 \pm 0.005, n=16 ; S_{5} 652 L_{L_{1}}-0.42 \pm 0.005^{* * *}, n=20 ; W_{S_{1}}-0.24 \pm 0.009, n=15 ; S 652 L_{S_{1}}-0.58 \pm 0.011^{* * *}, n=15\right)$ and $I_{C a}$ after $300 \mathrm{~ms}$ ([mean $\pm S E M ;$

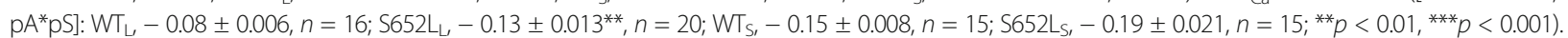
Data were collected from $>3$ independent transfections 
At low potentials, Cav1.3 channels can contribute to the formation of plateau potentials due to their known negative activation range (for a review, see [3]). This was described in medium spiny neurons when transient upstate potentials were induced by glutamatergic excitatory input [37]. To quantify changes of $\mathrm{I}_{\mathrm{Ca}}$ amplitudes induced by the mutation at sustained subthreshold depolarizations we mimicked plateau potentials by prolonged depolarizations to $-20 \mathrm{mV}$ with $15 \mathrm{mM} \mathrm{Ca}^{2+}$ as charge carrier. This voltage would correspond to $\sim-35-38 \mathrm{mV}$ at physiological $\mathrm{Ca}^{2+}$-concentrations [26] (Fig. 4a, b). The resulting $I_{\mathrm{Ca}}$ traces were normalized to maximal $I_{\mathrm{Ca}}$ at $V_{\max }$ in individual cells and corrected for splicing- and mutationdependent differences in $V_{0.5}$ by multiplying with the corresponding conductance measured for the different WT and mutant constructs at $-20 \mathrm{mV}$ (derived from activation curves in Fig. 1c, d). As shown in Fig. 4a, b, mutated channels caused a marked and highly significant increase of $I_{\mathrm{Ca}}$ over the first $300 \mathrm{~ms}$ of the depolarization compatible with enhanced channel activity suitable to support upstate potentials during this time period (for details, see legend to Fig. 4).

In order to predict the consequences of mutation S652L on $\mathrm{Ca}^{2+}$-influx during action potential firing we simultaneously measured $I_{\mathrm{Ca}}$ and cytosolic $\mathrm{Ca}^{2+}$ responses upon stimulation of HEK-293 cells transfected with $\mathrm{WT}_{\mathrm{L}}$ and $\mathrm{S} 652 \mathrm{~L}_{\mathrm{L}}$ with $10-\mathrm{Hz}$-trains of action potential-like waveforms (APW) (Fig. 5a; for details, see legend) $[26,38]$. These stimuli resulted in typical $I_{\mathrm{Ca}}$ transients (Fig. 5a) with maximal $I_{\mathrm{Ca}}$ reached during the repolarization phase of the APW $[29,38,39]$. Peak $I_{\mathrm{Ca}}$ slowly decreased during trains, an effect that was significantly enhanced by the mutation (Fig. 5a, b). However, the mutation enhanced the increase in intracellular $\mathrm{Ca}^{2+}$-levels measured simultaneously during this stimulation protocol (Fig. 5c). To explain this discrepancy, we measured the total $\mathrm{Ca}^{2+}$-charge during the $30-\mathrm{s}$ train. This was significantly higher in S652L mutated channels even after $15 \mathrm{~s}$ of stimulation (Fig. 5d; for details, see legend). It was not due to higher S652L channel expression, because we normalized data to current density for each cell. As shown in Fig. 5e, $I_{\mathrm{Ca}}$ amplitude during APW repolarization was significantly larger for $\mathrm{S} 652 \mathrm{~L}$ as compared to $\mathrm{WT}_{\mathrm{L}}$ (peak $1^{\text {st }} \mathrm{AP}[\mathrm{pA} / \mathrm{pF}]$ : $\mathrm{WT}_{\mathrm{L}}$, $12.43 \pm 1.95, n=19 ; \mathrm{S}^{2} 652 \mathrm{~L}_{\mathrm{L}},-33.64 \pm 3.13^{* * * * *}, n=$ 21; unpaired Student's $t$ test, $\left.{ }^{* * * *} p<0.001\right)$. This could be explained by the more negative activation voltage range as well as a pronounced slowing of $I_{\mathrm{Ca}}$ deactivation. Deactivation of tail currents following repolarizations from $+80 \mathrm{mV}$ to $-60 \mathrm{mV}$ or $-40 \mathrm{mV}$ was significantly slower in $\mathrm{S}^{2} 52 \mathrm{~L}_{\mathrm{L}}$ as compared to $\mathrm{WT}_{\mathrm{L}}$. This was primarily caused by a decrease in the contribution of the fast component and an increase of the slow component of the bi-exponential deactivation process (Fig. 5f; for statistics, see Table 3). Thus, higher $\mathrm{Ca}^{2+}$-levels and $\mathrm{Ca}^{2+}$-charge can be attributed to the slower deactivation kinetics and higher current amplitudes induced by mutation S652L during action potential like firing.

\section{Mutation S652W produces a loss of Cav1.3 channel function}

Our data predict that only CACNA1D mutations that are able to enhance Cav1.3 channel activity can confer high risk for neurodevelopmental symptoms. Accordingly, like any of the other previously described pathogenic variants, S652L has not been reported in the genomes of 141,456 control individuals free from pediatric disease (gnomAD database [21];). In contrast, the pathogenic potential should be low or absent from missense mutations causing gating defects favoring reduced function, as outlined above, in mice [40,41] and humans $[24,25]$. Interestingly, the gnomAD database also reports the rare variant p.Ser672Trp (chr3: $53757881 \mathrm{C}>\mathrm{G}$, human reference genome hg19) variant (S652W), located in the same position as $\mathrm{S} 652 \mathrm{~L}$, in three healthy unrelated individuals. PolyPhen2 and SIFT predict a probably damaging (score: 1.00) and deleterious (100\%) effect on protein function, respectively, but these algorithms cannot predict gating changes. This provided us with a unique opportunity to further test our above hypothesis by studying the biophysical properties of S652W. As shown in Fig. 6b, this mutation has opposite effects on the voltage-dependence of gating compared to S652L. Both steady-state activation and inactivation were significantly shifted to more positive voltages by $4-5 \mathrm{mV}$ (for statistics see Table 4).

Consequently, window currents were not increased and even tended to be shifted to more positive voltages also compatible with a loss-of-function at threshold voltages (Fig. 6c). S652W also failed to enhance channel function by other mechanisms: it did neither slow inactivation kinetics (Fig. 6d; for statistics, see Table 5) nor change the fraction of non-inactivating current as evident from the steady-state inactivation analysis (Fig. 6b).

\section{Molecular modeling of Cav1.3 WT, S652L, and S652W a $a_{1-}$ subunits}

On the structural level, the loss of a newly discovered inter-domain hydrogen bond connecting the S4-S5 linkers of repeats II and I could explain the gating differences between the two variants (Fig. 7). Our Cav1.3 channel homology model, based on the cryoEM structure of the Cav1.1 $\alpha_{1}$-subunit [30], localizes $\mathrm{S} 652$ at the C-terminal end of the S4-S5 linker in channel repeat II (Fig. 7, upper, left). The S4-S5 
A

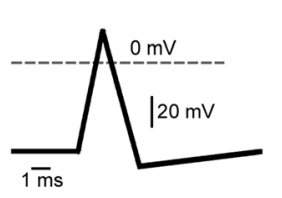

WTL
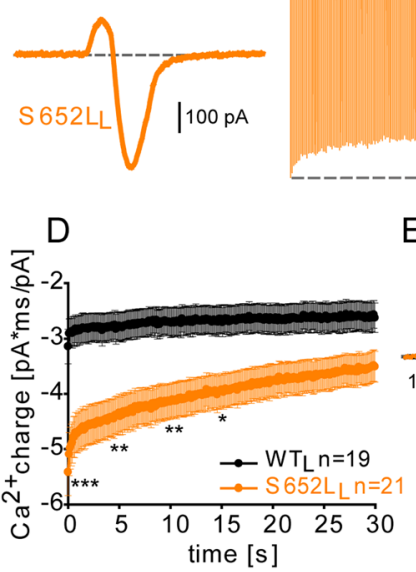

E
B

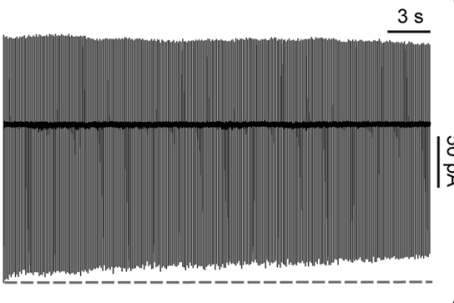

$\mid \begin{aligned} & 0 \\ & 0 \\ & D\end{aligned}$

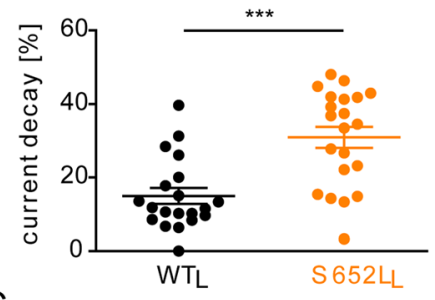

C

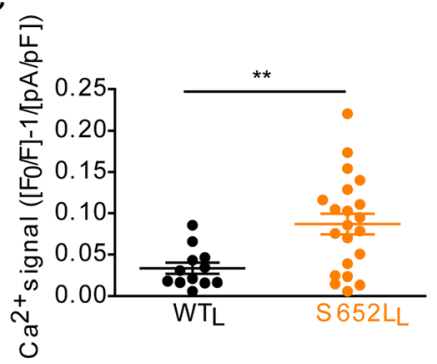

$\mathrm{F}$
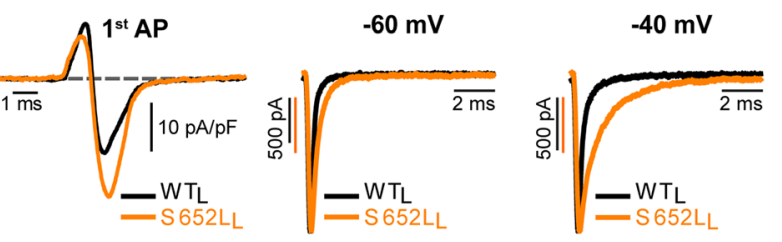

Fig. 5 Mutation S652L increases intracellular $\mathrm{Ca}^{2+}$ during simulated action potential firing. a Upper left: Shape of single action potential waveform (APW) mimicked by the following voltage steps: HP: $-80 \mathrm{mV},-80$ to $-60 \mathrm{mV}$ for $2.5 \mathrm{~ms},-60$ to $+20 \mathrm{mV}$ in $1 \mathrm{~ms}$, +20 to $-70 \mathrm{mV}$ in $1.5 \mathrm{~ms},-70$ to $-60 \mathrm{mV}$ in $5 \mathrm{~ms},-60 \mathrm{mV}$ for $90 \mathrm{~ms}$. The corresponding $I_{C a}$ of $W T_{L}$ and $S 652 L_{L}$ are shown below. Right: Representative current responses of $W T_{L}$ and $S 652 L_{L}$ during 30 s of stimulation with APW-like stimuli at a frequency of $10 \mathrm{~Hz}$. b Peak $I_{C_{a}}$ of S652L Cav1.3 channels decayed faster than WT during stimulation. Statistics: unpaired student's t-test ([mean \pm SEM]; WT $, 14.94 \pm 2.19, n=20 ; S 652 L_{L}, 30.94 \pm 2.85^{* * *}, n=21 ;{ }^{* * *} p<0.001$ ). c Average Ca ${ }^{2+}$-signal of $W T_{L}$ and $\mathrm{S}_{652 \mathrm{~L}_{L}}$ expressing HEK-293 cells upon $30 \mathrm{~s}$ of stimulation. $\mathrm{Ca}^{2+}$-signal was normalized to baseline fluorescence $\left(\mathrm{F}_{0}\left[\mathrm{mean} \pm \mathrm{SEM}\right.\right.$; $\mathrm{WT}_{\mathrm{L}}, 1.65 \pm 0.20$; $\left.\mathrm{S} 652 \mathrm{~L}_{\mathrm{L}}, 1.38 \pm 0.18\right)$ and current density $\left(\mathrm{pA} / \mathrm{pF}[\right.$ mean $\left.\pm \mathrm{SEM}] ; \mathrm{WT}_{\mathrm{L}}-11.93 \pm 1.46 ; \mathrm{S} 652 \mathrm{~L}_{\mathrm{L}}-8.51 \pm 1.04\right)$ determined in a ramp protocol before the start of the train. S652 $L_{L}$ Cav1.3 channels showed higher levels of $\left[\mathrm{Ca}^{2+}\right]$ than $W T_{L}$ after 30 s of stimulation. Statistics: unpaired Student's $t$ test, ${ }^{* *} p<0.01$. d Ca ${ }^{2+}-$ charge of $W T_{L}$ and $S 652 L_{L}$ obtained by integrating the area of the $I_{C_{a}}$ transient normalized to maximum $I_{C_{a}}$ determined in a ramp protocol before the start of the train. Statistics: two-way ANOVA of selected time points (every $5 \mathrm{~s}$ ), ${ }^{*} p<0.05$, ${ }^{* *} p<0.01,{ }^{* * *} p<0.001$. e Overlay of $1^{\mathrm{st}} \mathrm{AP}$ of $W T_{L}$ and $S 652 L_{L} I_{C a}$ transients normalized to current density ( $\mathrm{pA} / \mathrm{pF})$ determined in a ramp protocol before the start of the train to demonstrate larger APs induced by mutation S652L. f Normalized representative $I_{C a}$ transients of $W_{L}$ and S652 $L_{L}$ obtained from repolarisations from $+80 \mathrm{mV}$ to $-60 \mathrm{mV}$ (left) or $-40 \mathrm{mV}$ (right); scale bars correspond to the traces of the same color; for parameters and statistics see Table 3. The AP-like command voltage also triggered an outward current component occurring at the peak of the AP spike. We and others (see references in Ortner et al. [29]) have observed this previously. The outward component is likely composed of $\mathrm{Q}_{\mathrm{ON}}$ and a passive non-LTCC component (also found in non-transfected cells, [29])

Table 3 Tail current parameters of mutation S652L

\begin{tabular}{|c|c|c|c|c|c|c|c|c|}
\hline$a_{1}$-subunit & $T_{\text {fast }}(\mathrm{ms})$ & $\mathrm{T}_{\text {slow }}(\mathrm{ms})$ & $C(p A / p F)$ & $A_{\text {fast }}(p A / p F)$ & $A_{\text {slow }}(\mathrm{pA} / \mathrm{pF})$ & Half width (ms) & Norm. tail area (pA*ms) & $n$ \\
\hline \multicolumn{9}{|l|}{$-60 m V$} \\
\hline$W T_{L}$ & $0.16 \pm 0.01$ & $0.91 \pm 0.08$ & $-0.003 \pm 0.001$ & $-0.79 \pm 0.02$ & $-0.12 \pm 0.02$ & $0.31 \pm 0.02$ & $-0.44 \pm 0.02$ & 14 \\
\hline$S 652 L_{L}$ & $0.20 \pm 0.01^{*}$ & $0.81 \pm 0.04$ & $-0.007 \pm 0.001^{* *}$ & $-0.51 \pm 0.02^{* * *}$ & $-0.37 \pm 0.03^{* * *}$ & $0.41 \pm 0.02^{* * *}$ & $-0.65 \pm 0.03^{* * *}$ & 16 \\
\hline \multicolumn{9}{|l|}{$-40 \mathrm{mV}$} \\
\hline$W T_{L}$ & $0.19 \pm 0.02$ & $1.12 \pm 0.07$ & $-0.006 \pm 0.001$ & $-0.65 \pm 0.02$ & $-0.24 \pm 0.01$ & $0.37 \pm 0.02$ & $-0.65 \pm 0.04$ & 14 \\
\hline $\mathrm{S} 652 \mathrm{~L}_{\mathrm{L}}$ & $0.39 \pm 0.03^{* * *}$ & $1.95 \pm 0.08^{* * *}$ & $-0.047 \pm 0.003^{* * *}$ & $-0.29 \pm 0.02^{* * *}$ & $-0.54 \pm 0.02^{* * *}$ & $0.92 \pm 0.07^{* * *}$ & $-1.87 \pm 0.09^{* * *}$ & 16 \\
\hline
\end{tabular}

Normalized tail currents were fitted to a bi-exponential decay $\left(\tau_{\text {fast, }} \tau_{\text {slow: }}\right.$ time constants of slow and fast component; $A_{\text {fast }}, A_{\text {slow: }}$ amplitudes of slow and fast components; C: non-inactivating component). Statistics: Mann-Whitney $U$ test, ${ }^{*} p<0.05,{ }^{* *} p<0.01,{ }^{* * *} p<0.001$. All values are presented as mean \pm SEM (> 3 independent transfections). $n$, number of recordings 


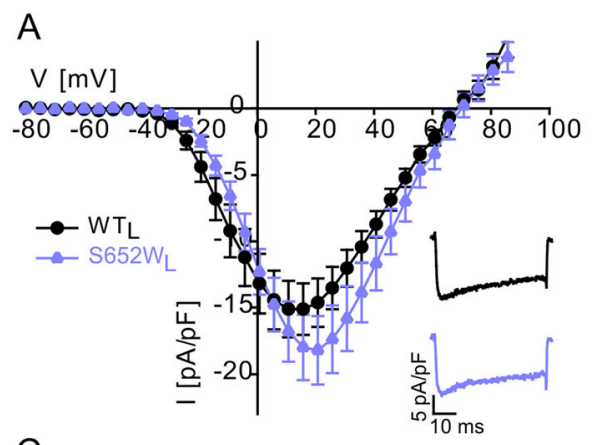

C
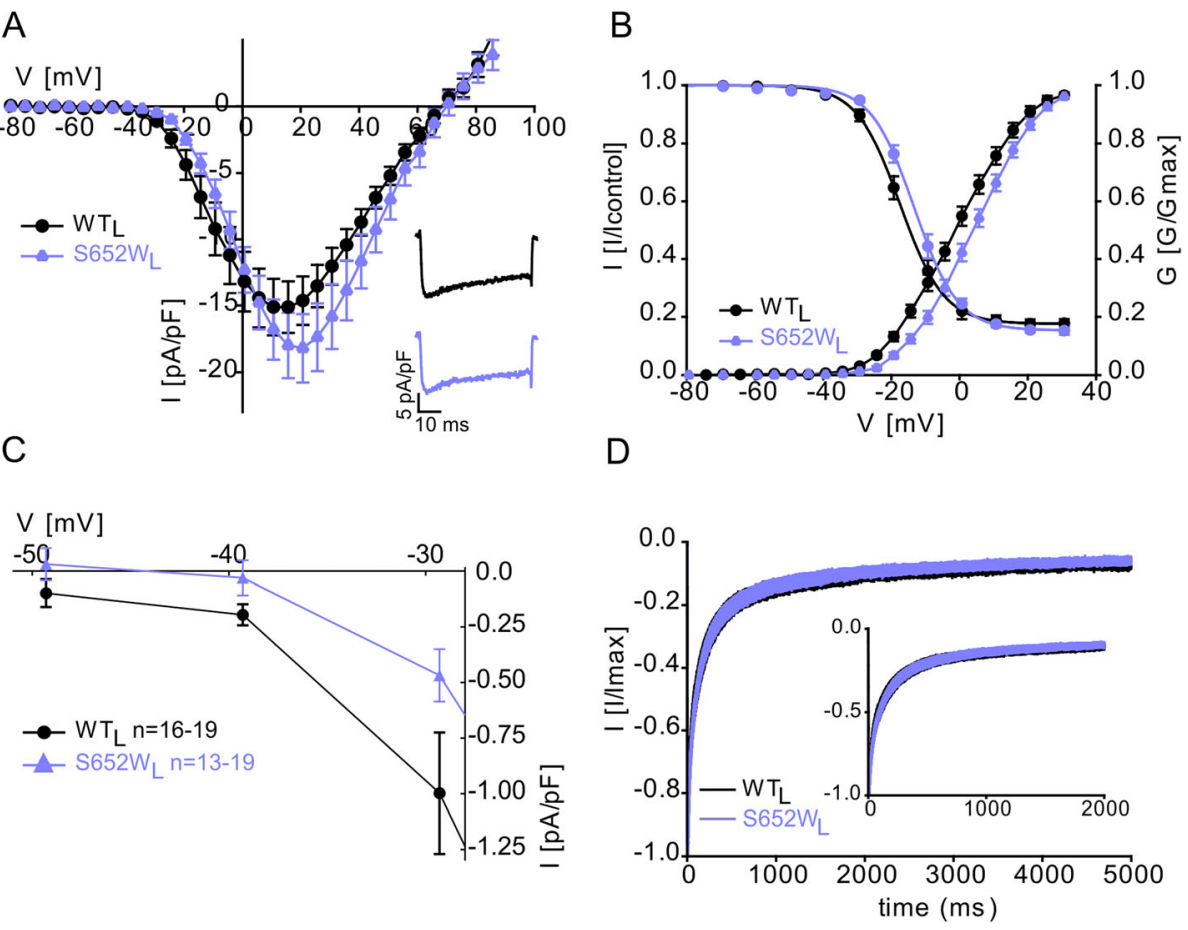

Fig. 6 Mutation S652W induces gating changes compatible with a loss-of-function phenotype. a Current-voltage relationship (lCai mean \pm SEM) of WT vs $S 652 W_{L}$ recorded in parallel on the same day as described in Fig. 1. Inset: Representative $I_{C a}$ traces of $W T_{L}$ and $S 652 W_{L}$ upon depolarization to the $V_{\text {max }}$. b Normalized steady-state activation and inactivation curves of $W_{L}$ vs $S 652 W_{L}$. Data are presented as mean \pm SEM; for parameters and statistics see Table 4. c Window currents of $W_{L}$ vs $S 652 W_{L}$ were calculated as in Fig. 1e, f. Data are presented as means for the indicated number of experiments. $\mathbf{d}$ Inactivation kinetics of $W_{L}$ vs. $5652 W_{L}$ during a 5-s depolarization to $V_{\max }$ with $\mathrm{Ca}^{2+}$ as a charge carrier showing no difference in inactivation kinetics between $W_{L}$ and $S 652 W_{L}$. Inset shows the first 2000 ms. Data are presented as mean \pm SEM; for statistics and number of experiments, see Table 5. The significant shift of activation and inactivation half-maximal voltage to positive voltages and the absence of a change in inactivation time course was independently confirmed in an independent set of experiments using HEK-293 cells stably expressing $\beta_{3}$ and a2 $\delta-1$ subunits with essentially identical results. Statistics: one-way ANOVA followed by Bonferroni post hoc test, ${ }^{*} p<0.05$. Data are represented as mean \pm SEM for the $n$-numbers indicated. Data were collected from $>3$ independent transfections

linkers in each repeat are known to form contacts with the cytoplasmic end of their corresponding S6 helices, which together form the inner mouth of the channel (activation gate [30];). This allows the S4-S5 linkers to transmit voltage-sensor movements to the activation gate. Our model predicts that $\mathrm{S} 652$ forms a hydrogen bond with S256 in the S4-S5 linkers of the neighboring repeat I (Fig. 7a). Therefore, this hydrogen bond connects the S4-S5 linkers in two different repeats and could be crucial for controlling the voltage-sensitivity of channel gating. This is supported by our finding that in the S652L mutant, this inter- domain interaction is not stabilized by any hydrogen bonds. Instead, leucine forms much weaker hydrophobic contacts with the residues V259, V260, and L261 located in the S4-S5 linkers of repeat I (Fig. 7b). In contrast, the aromatic side chain of the tryptophan in the S652 W mutant is capable of forming an interdomain pi-H interaction with S256 in IS4-S5 as well as an intra-domain hydrogen bond with its own IIS4S5 backbone (K648) (Fig. 7c), which should also allow a rigidifying effect similar as in the WT channel.

Together with our functional data, this reveals the importance of an inter-domain hydrogen bond for normal

Table 4 Activation and inactivation parameters of mutation S652W

\begin{tabular}{|c|c|c|c|c|c|c|c|c|}
\hline \multirow[b]{2}{*}{$a_{1}$-subunit } & \multicolumn{4}{|l|}{ Activation } & \multicolumn{4}{|l|}{ Inactivation } \\
\hline & $\mathrm{V}_{0.5}(\mathrm{mV})$ & $\mathrm{k}(\mathrm{mV})$ & $\mathrm{V}_{\text {rev }}(\mathrm{mV})$ & $\mathrm{n}$ & $V_{0.5, \text { inact }}(\mathrm{mV})$ & $\mathrm{k}(\mathrm{mV})$ & Non-inactivating (\%) & $n$ \\
\hline$W T_{L}$ & $-0.50 \pm 1.48$ & $9.32 \pm 0.26$ & $67.1 \pm 1.60$ & 19 & $-17.5 \pm 1.32$ & $5.94 \pm 0.28$ & $17.4 \pm 1.45$ & 16 \\
\hline S652 Wh & $4.23 \pm 1.27^{*}$ & $8.73 \pm 0.22$ & $64.6 \pm 2.12$ & 19 & $-13.1 \pm 1.22^{*}$ & $5.73 \pm 0.30$ & $15.1 \pm 1.06$ & 13 \\
\hline
\end{tabular}

Parameters were obtained by fitting normalized activation curves $\left(G / G_{\max }\right)$ or inactivation curves $\left(I / I_{\text {control }}\right)$ as in Table 1 . All values are presented as mean \pm SEM $(>$ 3 independent transfections). Statistics: unpaired Student's $t$ test, ${ }^{*} p<0.05$ compared to $\mathrm{WT}_{\mathrm{L}}$. $n$, number of recordings. $V_{0.5}$, half maximal activation/inactivation voltage; $V_{\text {rev }}$ reversal potential; $W T$, wild- type 
Table 5 Normalized inactivation kinetic parameters of mutation S652W

\begin{tabular}{|c|c|c|c|c|c|c|c|}
\hline \multirow[b]{2}{*}{$a_{1}$-subunit } & \multicolumn{7}{|c|}{ Remaining $I_{\mathrm{Ca}}[\%]$} \\
\hline & $r_{50}$ & $r_{100}$ & $r_{250}$ & $r_{500}$ & $r_{1000}$ & $r_{5000}$ & $n$ \\
\hline$\overline{W T_{L}}$ & $60.45 \pm 4.22$ & $47.88 \pm 4.09$ & $30.88 \pm 3.21$ & $20.44 \pm 2.26$ & $14.61 \pm 1.85$ & $7.59 \pm 0.86$ & 11 \\
\hline$S 652 W_{L}$ & $62.86 \pm 2.34$ & $49.49 \pm 2.35$ & $31.35 \pm 2.13$ & $20.61 \pm 1.99$ & $13.85 \pm 1.53$ & $6.35 \pm 0.74$ & 13 \\
\hline
\end{tabular}

$r$ values represent the fraction of remaining $I_{\mathrm{Ca}}$ after $50,100,250,500,1000$, and $5000 \mathrm{~ms}$ upon a 5 -s depolarization to the voltage of maximal inward current $\left(V_{\max }\right)$. All values are presented as meanM ( $>3$ independent transfections). No significant differences were found by unpaired Student's $t$ test of $r$ values, compared to $\mathrm{WT}_{\mathrm{L}}$. $n$, number of recordings; $W T$, wild-type

electromechanical coupling in Cav1.3 channels, which has not been described before. Weakening this interaction by substituting $\mathrm{S} 652$ with leucine causes a dramatic change in channel gating. Since we modeled the mutation with the activation gate in a closed channel conformation, this hydrogen bond likely stabilizes the channel in a closed state. Its weakening would favor the transition to and/or the stabilization in the open state, which can explain the strong shift of the voltagedependence of activation to more negative potentials. Stabilization of the open state can also explain the slower transition from the open to the closed state evident as slowing of deactivation in the S652L mutant channel at a given voltage.

\section{Mutation S652L increases the sensitivity of Cav1.3 channels for inhibition by the dihydropyridine LTCC blocker isradipine}

The fact that pathogenicity is associated with enhanced channel function but that reduced Cav1.3 channel function in the brain is not associated with CNS symptoms (see above), make available LTCC blockers a potential therapeutic option for the symptomatic treatment of individuals affected by gain-of-function mutations.

These drugs, such as the dihydropyridines (DHPs) nifedipine, felodipine, or isradipine, are safely used since decades for the treatment of arterial hypertension and angina. Since DHPs preferentially bind to channels in an inactivated state [42, 43], mutations affecting the gating properties, such as S652L may change the sensitivity of the channel for inhibition by DHPs. In order to quantify mutation-induced changes on DHP sensitivity, we assessed inhibition of the Cterminally long WT and S652L mutant channels by the DHP isradipine using a standard square pulse protocol $\left(100 \mathrm{~ms}\right.$ to $\left.V_{\max }, 0.1 \mathrm{~Hz}, \mathrm{HP}:-89 \mathrm{mV}\right)$. As illustrated in Fig. 8, S652L-mutated channels required significantly lower isradipine concentrations for channel inhibition with a 3-4-fold decrease of their half maximal inhibitory concentration ( $\mathrm{IC}_{50}$, mean $(95 \%$ coincidence interval); $\mathrm{WT}_{\mathrm{L}}: 60.3(52.0-70.0) \mathrm{nM}$,

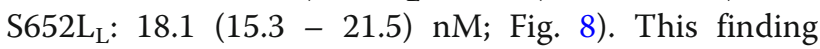
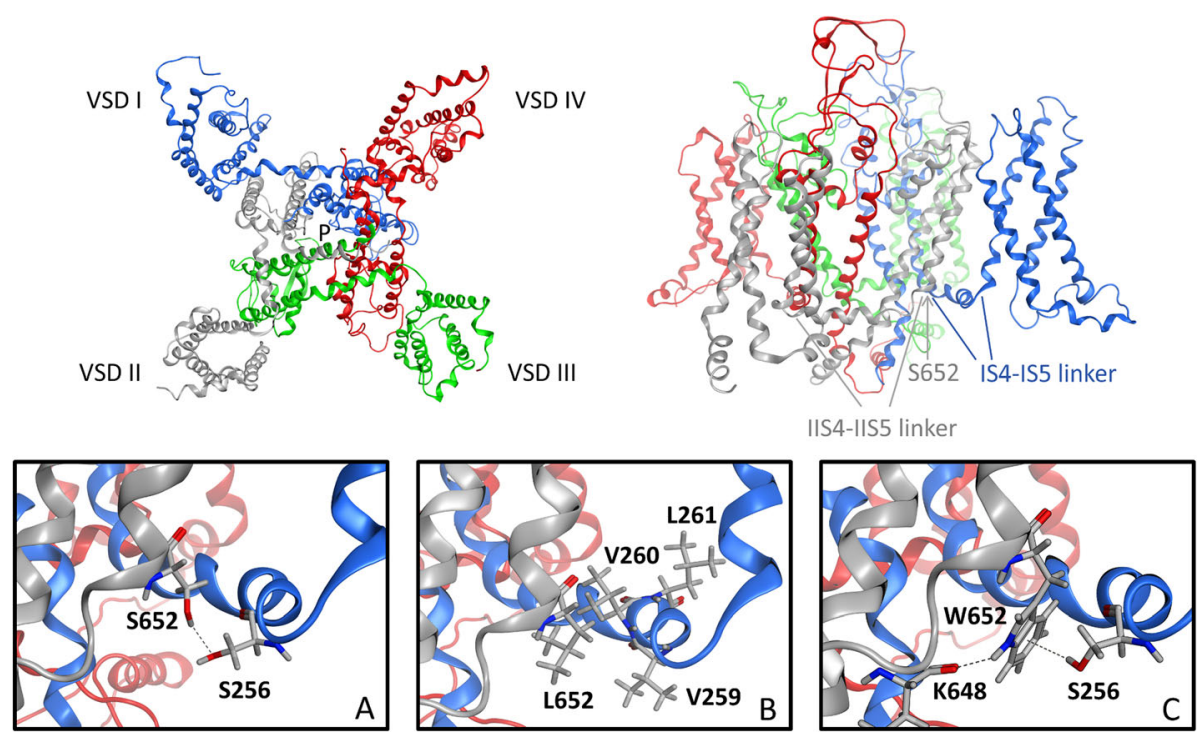

Fig. 7 Molecular modeling of Cav1.3 WT $a_{1}$-subunits, mutations S652L and S652W. Top: Top view and side view of the Cav1.3 $a_{1}$-subunit structure. The region involving the inter-domain interactions (IIS4-S5-IS4-IS5) affected by the mutation is highlighted (left). Bottom: a WT inter-domain interaction of S652 in repeat II and S256 in the S4-S5 linker in repeat I. b Weaker hydrophobic interactions of the mutated residue L652 with the hydrophobic cloud in the S4-S5 linker of repeat I. c Stabilizing effect of the W652 mutation; the tryptophan residue can form an intra-domain hydrogen bond with the backbone of K648 and due to its aromatic character an inter-domain pi-H interaction with S256. 


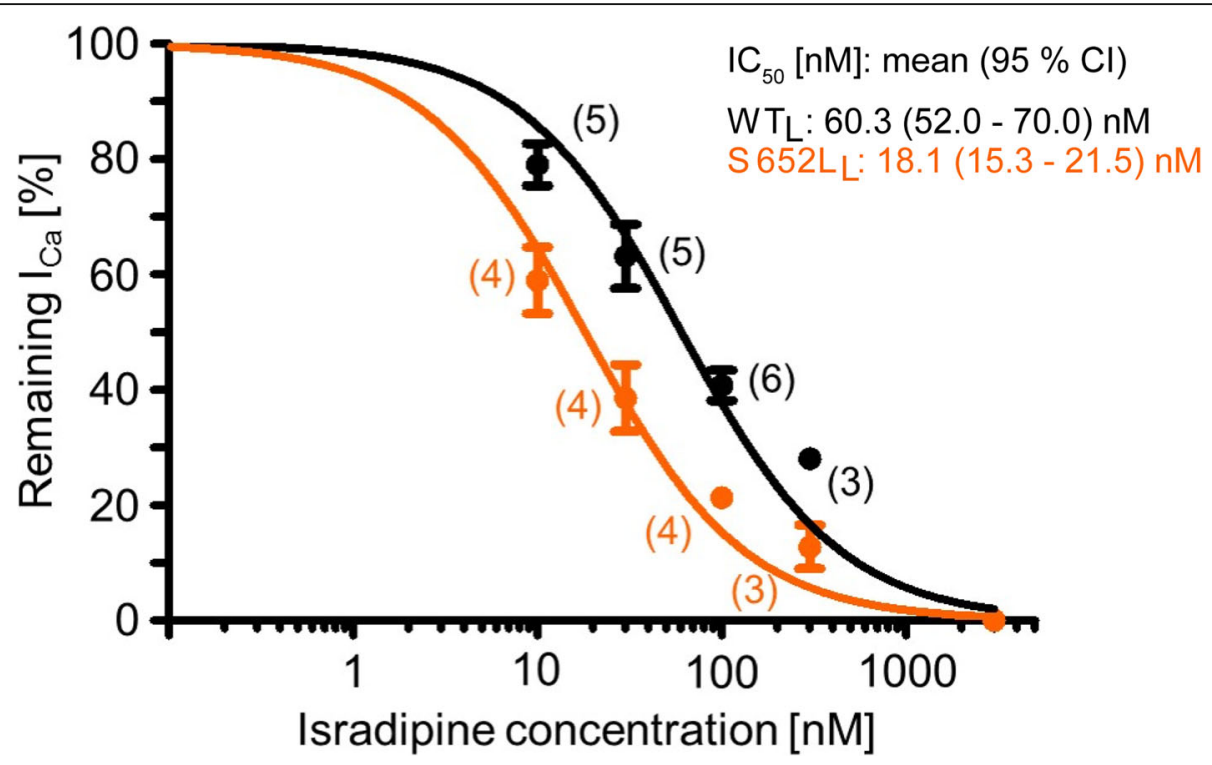

Fig. 8 Mutation S652L shows higher isradipine sensitivity. Concentration-response curves for $W T_{L}$ and S652 $L_{L}$ steady-state $I_{C a}$ inhibition by isradipine. Data are presented as mean \pm SEM for the $n$-numbers indicated. Curves were fitted using a Hill slope $=1$ and top-bottom fixed (bottom $=0$; top $=100$ ). $I C_{50}$ values are given as means with 95\% confidence interval. The statistical significance was determined using the extra sum-of-squares $F$ test $(p<0.0001)$.

suggests that DHPs with good brain penetrance, such as isradipine $[29,44]$ may preferentially inhibit S652L-mutated Cav1.3 channels. Based on their good clinical safety profile this encourages therapeutic trials with DHPs in the affected individuals.

\section{Discussion}

In this study, we provide compelling evidence for the CACNA1D S652L variant as a high-risk and likely disease-causing mutation in two individuals of the Deciphering Developmental Disorders cohort (decipher.sanger.ac.uk) of children with severe, undiagnosed developmental disorders [23]. This evidence builds on a detailed biophysical characterization that demonstrates gating changes able to also induce enhanced channel activity as is typical for six other de novo germline missense mutations in patients with ASD with and without other neurodevelopmental symptoms [14-18, 20]. Our data adds the CACNA1D gene to the other 12 developmental-disorder-linked genes identified in the Deciphering Developmental Disorders study and thus further increases its diagnostic yield. Moreover, since S652L has also been found in APAs as a somatic mutation we also confirm $\mathrm{S} 652 \mathrm{~L}$ as a disease-causing mutation in patients with primary aldosteronism [33]. We also demonstrate that although heterozygous missense mutations in the same position can be damaging, they can have opposite effects on channel function and, in the case of Cav1.3 $\alpha_{1}$-subunits, may comprise low or no pathogenic risk when the resulting gating changes does not support a gain-of-function. This complicates predictions of the disease-causing role of rare de novo CACNA1D variants in genetic studies and emphasizes the need for functional analysis as described in this report. We clearly show this for S652W. Whereas neither S652L nor one of the other pathogenic CACNA1D mutations is reported in the gnomAD database, the heterozygous $\mathrm{S} 652 \mathrm{~W}$ variant is reported in three neurologically apparently healthy individuals in this database [21]. In contrast to S652L, this variant tended to shift the window current to more positive rather than negative voltages, which is due to the positive shift of the voltagedependence of activation and inactivation. This nicely fits our prediction that only CACNA1D mutations which can also support channel gain-of-function confer high risk for neurodevelopmental disorders. It is also in line with previous studies in mice (for a review, see [3]) and humans $[24,25]$. These found that heterozygous loss-offunction of Cav1.3 is unlikely to cause symptomatic neurodevelopmental disorders and even homozygous loss of Cav1.3 function has not been reported to cause neuropsychiatric behavioral changes [3, 24, 25, 41]. Therefore, a unifying feature of all pathogenic mutations described so far is the potential to induce gating changes that can enhance Cav1.3 function during neuronal activity. The potential for enhanced channel function may, however, vary between different neurons. For example, in neurons firing from more depolarized membrane potentials, the negative shift in steady-state inactivation may also reduce the availability of Cav1.3 channels.

S652L adds to another six de novo missense mutations functionally characterized so far by us [14-16] and 
others $[17,18,20,38]$ in a total of seven patients with neurodevelopmental disorders. Functionally they fall into two major classes. Channel gain-of-function is either predominantly induced by stabilizing a large noninactivating current component (type 1: in particular, G403D, G407R) or by inducing a strong shift of activation voltage to more negative potentials (type 2: A749G, I750M and V401L) [14-17], as also observed for S652L. Both types of mutations enhance intracellular $\mathrm{Ca}^{2+}$-load when expressed in HEK-293 (A749G, [38]; S652L, this paper) or GLT muscle cells (G407R, [14]). Pronounced negative shifts of activation and/or pronounced slowing of channel inactivation can therefore be taken as "diagnostic" feature for the pathogenicity of CACNA1D de novo mutations in patients with neurodevelopmental disease.

Importantly, our data also strongly suggest that pathogenicity can also be assumed if the same variant has also been reported as a somatic mutation in APAs. As shown here, this is the case for S652L [33] and likewise for G403D, I750M and V401L [17, 45].

We have also observed a small but significant shift of $V_{\text {rev }}$ (Fig. 1, Table 1) to more negative voltages. This could indicate a potential change in ion selectivity by the mutation. Interestingly, we have also detected similar shifts by other Cav1.3 $\alpha_{1}$-subunit gain-of-function mutations [16]. If confirmed by single-channel recordings, this may also contribute to the mutation-induced pathological signaling changes.

Very recently identified de novo mutation V259A has been reported in another severely affected individual, a 1-year-old male with seizures, global developmental delay and primary aldosteronism [19]. So far this mutation has not been functionally characterized. Although its pathogenic potential appears to be high based on two different APA mutations reported in the same position (V259D, V259G) [46]), final proof requires functional analysis as described here.

Finally, another important and clinically highly relevant result of our study was the observation that Cav1.3 channels harboring the S652L-mutation require lower concentrations of the DHP isradipine for inhibition. This can be explained by the known voltage-dependence of DHP action due to their preferred binding to inactivated channel states $[29,42]$. S652L induces a pronounced negative shift of the voltage-dependence of inactivation thus increasing the availability of inactivated channels. This preclinical finding is a strong motivation to test if repurposing of already available DHPs could ameliorate symptoms in affected individuals. Since also other mutations inducing strong shifts in steady-state inactivation are likely to increase DHP sensitivity (e.g.
A749G, [14]), this treatment approach, if successful, could also be offered to individuals with other CACNA1D mutations.

\section{Limitations}

Although our data strongly support CACNA1D as a high-risk gene for neurodevelopmental disorders and emphasize the need of functional analysis to distinguish likely pathogenic (able to increase Cav1.3 activity) from non-pathogenic de novo mutations (unable to increase Cav1.3 activity), our studies do not provide insight into altered signaling cascades downstream of Cav1.3 channels. This will require introduction of one or more of these human mutations into the mouse Cacnald gene for electrophysiological and biochemical studies in native cells. Such animal models will also allow to address the important question, if currently available LTCC blocker, such as isradipine, felodipine of nimodipine, can normalize cellular function and, perhaps, even behavioral phenotypes in these mice. Although LTCC blockers may normalize the mutation-induced increase in channel function after diagnosis, it is possible that the mutation may have already caused permanent developmental deficiencies resistant to drug treatment. Therefore the clinical potential of this therapy needs to be tested in small clinical trials in affected individuals.

\section{Conclusions}

Taken together our data have important implications for genetic diagnostics. We provide evidence that $C A C N$ $A 1 D$ is a neurodevelopmental disorder-linked gene. Although initially considered to cause high risk only for ASD with or without intellectual disability [14], the increasing number of affected individuals, including S652L, now strongly indicates that the majority presents with a more severe phenotype. This can involve seizures, intellectual disability and, due to the role of Cav1.3 for aldosterone and insulin secretion [40, 46]), also with (often transient, [17, 18]) endocrine symptoms. Our findings with S652W (the loss-of-function mutation) emphasize that, in the case of CACNA1D, the amino acid position itself does not allow predictions about the disease risk of a variant, even if bioinformatics prediction tools provide high scores for protein damage. A high probability for pathogenicity can also be assumed if a variant identical to the germline mutation has also been found in at least two different individuals as a somatic mutation in an APA or an aldosterone-producing cellcluster [34, 47, 48]. Our report should raise awareness for the pathogenic potential of CACNA1D mutations, especially in patients without additional congenital endocrine symptoms as diagnostic features. At present, de 
novo CACNA1D missense mutations may be underdiagnosed in clinical practice.

\section{Supplementary information}

Supplementary information accompanies this paper at https://doi.org/10. 1186/s13229-019-0310-4.

Additional file 1: Figure S1. Expression of WT and S652L Cav1.3 $a_{1}$ subunits in HEK-293 cells. (A) Expression of C-terminally long and short $\mathrm{WT}$ and $\mathrm{S} 652 \mathrm{~L} \mathrm{a}_{1}$-subunits by Western blot analysis. One representative Western blot of $>3$ experiments from $>2$ membrane preparations of transfected HEK-293 cells stably expressing $\beta_{3}$ and $a_{2} \delta-1$ is shown. The apparent molecular mass of the full length forms of the long and short Cav1.3 $a_{1}$-subunit splice variants obtained under our experimental conditions is indicated. (B) Quantification of relative total protein expression levels was carried out by integrating densities of WT and mutant signals and normalization to the loading control a-tubulin (a-tub). Statistics: unpaired student's t-test compared to WT (S652 L : $118.26 \pm 23.43, n=4$; S652 Ls: $129.62 \pm 8.94, n=3)$. Data are presented as mean \pm SEM.

Additional file 2: Figure S2. Relationship of $\mathrm{Q}_{\mathrm{ON}}$-gating charge movement and integrated tail current amplitude $\left(\left.\right|_{\text {tail }}\right)$ as an indirect estimate of open probability. (A) Channel open probability was estimated from the slope of the $\mathrm{QON}^{-1} \mathrm{I}_{\text {tail }}$ relationships measured at $\mathrm{V}_{\text {rev }}$. Slopes were obtained by linear regression: $\mathrm{I}_{\text {tail }} / \mathrm{Q}_{\mathrm{ON}}\left[\right.$ mean $\left.\pm \mathrm{SEM} ; \mathrm{ms}^{-1}\right]$ : $\mathrm{WT}_{\mathrm{L}}:-7.22 \pm$ $0.916, r^{2}=0.72, n=26$; S652L $:-4.24 \pm 0.657, r^{2}=0.72, n=25$; slopes are significantly different: $F=6.43, p=0.015, F$ test). (B) Representative traces obtained by depolarization to the reversal potential from a HP of $-89 \mathrm{mV}$. Data were collected from more than three independent transfections.

\section{Abbreviations}

APA: Aldosterone-producing adenoma; APW: Action potential-like waveform; ASD: Autism spectrum disorder; Cav: Voltage-gated $\mathrm{Ca}^{2+}$-channel; $\mathrm{CDI}: \mathrm{Ca}^{2+}{ }_{-}$ dependent inactivation; CNS: Central nervous system; DHP: Dihydropyridine; G: Conductance; HEK: Human embryonic kidney; HP: Holding potential; $I_{\mathrm{Ba}}$ Inward $\mathrm{Ba}^{2+}$-currents; $I_{\mathrm{Ca}}$ : Inward $\mathrm{Ca}^{2+}$-currents; $P_{\mathrm{O}}$ : Open probability; $Q_{\mathrm{ON}}:$ "ON" gating charge; $V_{0.5}$ : Half-maximal activation voltage; VDI: Voltagedependent inactivation; VGCC: voltage-gated $C^{2+}{ }^{2+}$-channel; $V_{\text {max }}$ : Potential of maximal inward current; $V_{\text {rev }}$ : Reversal potential; WT: Wild-type

\section{Acknowledgements}

We thank Jennifer Müller, Gospava Stojanovic, Bettina Tschugg for expert technical assistance. The Deciphering Developmental Disorders study presents independent research commissioned by the Health Innovation Challenge Fund [grant number HICF-1009-003], a parallel funding partnership between Wellcome and the Department of Health, and the Wellcome Sanger Institute [grant number WT098051]. The views expressed in this publication are those of the author(s) and not necessarily those of Wellcome or the Department of Health. The research team acknowledges the support of the National Institute for Health Research, through the Comprehensive Clinical Research Network.

\section{Authors' contributions}

NTH performed all electrophysiological experiments of mutation S652L, analyzed and interpreted data, and drafted and revised the manuscript. YVN characterized mutation S652W and analyzed data. NJO performed pharmacological experiments and analyzed data. MLFQ, KRL, and BEF provided molecular models and interpreted data. PT helped with $\mathrm{Ca}^{2+}$ imaging experiments and interpretation of the data. HC provided novel clinical data of the two patients and revised the manuscript. JS designed the study, analyzed and interpreted data and revised the manuscript for important intellectual content. All authors approved the final version of the manuscript.

\section{Funding}

This work was supported by grants of the Austrian Science Fund (FWF, P27809, W1101, DOC 30/CavX).

\section{Availability of data and materials}

The datasets generated and/or analyzed during the current study are available from the corresponding author on reasonable request.

\section{Ethics approval and consent to participate}

The Deciphering Developmental Disorders Study [23] has UK Research Ethics Committee approval (10/H0305/83, granted by the Cambridge South REC, and GEN/284/12, granted by the Republic of Ireland REC). Parental informed consent has been obtained for updated clinical information of the probands.

\section{Consent for publication}

Parental consent was obtained for anonymized data being included in publications.

\section{Competing interests}

The authors declare that they have no competing interests.

\section{Author details}

${ }^{1}$ Department of Pharmacology and Toxicology, Centre for Molecular Biosciences, University of Innsbruck, Innrain 80/82, 6020 Innsbruck, Austria. ${ }^{2}$ Institute of General, Inorganic and Theoretical Chemistry, Centre for Molecular Biosciences, University of Innsbruck, Innsbruck, Austria. ${ }^{3}$ Division of Physiology, Department of Physiology and Medical Physics, Medical University Innsbruck, 6020 Innsbruck, Austria. ${ }^{4}$ West Midlands Regional Clinical Genetics Service, Birmingham Women's and Children's Hospital, National Health Service Foundation Trust, B15 2TG, Birmingham, UK.

Received: 4 October 2019 Accepted: 24 December 2019

Published online: 08 January 2020

\section{References}

1. Nanou E, Catterall WA. Calcium Channels, Synaptic Plasticity, and Neuropsychiatric Disease. Neuron. 2018;98(3):466-81.

2. Dolphin AC. Voltage-gated calcium channels and their auxiliary subunits: physiology and pathophysiology and pharmacology. J Physiol. 2016;594(19): 5369-90.

3. Zamponi GW, Striessnig J, Koschak A, Dolphin AC. The Physiology, Pathology, and Pharmacology of Voltage-Gated Calcium Channels and Their Future Therapeutic Potential. Pharmacol Rev. 2015;67(4):821-70.

4. Striessnig J, Pinggera A, Kaur G, Bock G, Tuluc P. L-type Ca ${ }^{2+}$ channels in heart and brain. Wiley Interdiscip Rev Membr Transp Signal. 2014;3(2):15-38.

5. Cohen SM, Li B, Tsien RW, Ma H. Evolutionary and functional perspectives on signaling from neuronal surface to nucleus. Biochem Biophys Res Commun. 2015;460(1):88-99.

6. Alexander SP, Striessnig J, Kelly E, Marrion NV, Peters JA, Faccenda E, et al. THE CONCISE GUIDE TO PHARMACOLOGY 2017/18: Voltage-gated ion channels. Br J Pharmacol. 2017:174(Suppl 1):S160-s94.

7. Heyes S, Pratt WS, Rees E, Dahimene S, Ferron L, Owen MJ, et al. Genetic disruption of voltage-gated calcium channels in psychiatric and neurological disorders. Prog Neurobiol. 2015;134:36-54.

8. Moon AL, Haan N, Wilkinson LS, Thomas KL, Hall J. CACNA1C: Association With Psychiatric Disorders, Behavior, and Neurogenesis. Schizophr Bull. 2018; 44(5):958-65.

9. Kabir ZD, Martinez-Rivera A, Rajadhyaksha AM. From Gene to Behavior: LType Calcium Channel Mechanisms Underlying Neuropsychiatric Symptoms. Neurotherapeutics. 2017;14(3):588-613.

10. Splawski I, Timothy KW, Sharpe LM, Decher N, Kumar P, Bloise R, et al. Cav1. 2 calcium channel dysfunction causes a multisystem disorder including arrhythmia and autism. Cell. 2004;119(1):19-31.

11. Splawski I, Timothy KW, Decher N, Kumar P, Sachse FB, Beggs AH, et al. Severe arrhythmia disorder caused by cardiac L-type calcium channel mutations. Proc Natl Acad Sci U S A. 2005;102(23):8089-96 discussion 6-8.

12. Gillis J, Burashnikov E, Antzelevitch C, Blaser S, Gross G, Turner L, et al. Long QT, syndactyly, joint contractures, stroke and novel CACNA1C mutation: expanding the spectrum of Timothy syndrome. Am J Med Genet A. 2012; $158 \mathrm{a}(1): 182-7$

13. Atkinson LZ, Colbourne L, Smith A, Harmer $\mathrm{CH}$, Nobre AC, Rendell J, et al. The Oxford study of Calcium channel Antagonism, Cognition, Mood instability and Sleep (OxCaMS): study protocol for a randomised controlled, experimental medicine study. Trials. 2019;20(1):120. 
14. Pinggera A, Lieb A, Benedetti B, Lampert M, Monteleone S, Liedl KR, et al. CACNA1D de novo mutations in autism spectrum disorders activate Cav1.3 L-type calcium channels. Biol Psychiatry. 2015;77(9):816-22.

15. Pinggera A, Mackenroth L, Rump A, Schallner J, Beleggia F, Wollnik B, et al. New gain-of-function mutation shows CACNA1D as recurrently mutated gene in autism spectrum disorders and epilepsy. Hum Mol Genet. 2017; 26(15):2923-32.

16. Pinggera A, Negro G, Tuluc P, Brown MJ, Lieb A, Striessnig J. Gating defects of disease-causing de novo mutations in Cav1.3 $\mathrm{Ca}^{2+}$ channels. Channels (Austin). 2018;12(1):388-402.

17. Scholl UI, Goh G, Stolting G, de Oliveira RC, Choi M, Overton JD, et al. Somatic and germline CACNA1D calcium channel mutations in aldosterone-producing adenomas and primary aldosteronism. Nat Genet. 2013;45(9):1050-4.

18. Flanagan SE, Vairo F, Johnson MB, Caswell R, Laver TW, Lango Allen $H$, et al. A CACNA1D mutation in a patient with persistent hyperinsulinaemic hypoglycaemia, heart defects, and severe hypotonia. Pediatr Diabetes. 2017; 18(4):320-3

19. Semenova NA, Ryzhkova OR, Strokova TV, Taran NN. The third case report a patient with primary aldosteronism, seizures, and neurologic abnormalities (PASNA) syndrome de novo variant mutations in the CACNA1D gene. Zh Nevrol Psikhiatr Im S S Korsakova. 2018;118(12):49-52.

20. Garza-Lopez E, Lopez JA, Hagen J, Sheffer R, Meiner V, Lee A. Role of a conserved glutamine in the function of voltage-gated $\mathrm{Ca}^{2+}$ channels revealed by a mutation in human CACNA1D. J Biol Chem. 2018;293(37): $14444-54$.

21. Karczewski KJ, Francioli LC, Tiao G, Cummings BB, Alföldi J, Wang Q, et al. Variation across 141,456 human exomes and genomes reveals the spectrum of loss-of-function intolerance across human protein-coding genes. bioRxiv. 2019:531210.

22. Iossifov I, Ronemus M, Levy D, Wang Z, Hakker I, Rosenbaum J, et al. De novo gene disruptions in children on the autistic spectrum. Neuron. 2012; 74(2):285-99.

23. The Deciphering Developmental Disorders S. Large-scale discovery of novel genetic causes of developmental disorders. Nature. 2015;519(7542):223-8.

24. Baig SM, Koschak A, Lieb A, Gebhart M, Dafinger C, Nurnberg G, et al. Loss of Cav1.3 (CACNA1D) function in a human channelopathy with bradycardia and congenital deafness. Nat Neurosci. 2011;14(1):77-84.

25. Liaqat K, Schrauwen I, Raza SI, Lee K, Hussain S, Chakchouk I, et al. Identification of CACNA1D variants associated with sinoatrial node dysfunction and deafness in additional Pakistani families reveals a clinical significance. J Hum Genet. 2019;64(2):153-60.

26. Bock G, Gebhart M, Scharinger A, Jangsangthong W, Busquet P, Poggiani $C$, et al. Functional properties of a newly identified C-terminal splice variant of Cav1.3 L-type $\mathrm{Ca}^{2+}$ channels. J Biol Chem. 2011;286(49):42736-48.

27. Koschak A, Reimer D, Huber I, Grabner M, Glossmann H, Engel J, et al. alpha 1D (Cav1.3) subunits can form L-type $\mathrm{Ca}^{2+}$ channels activating at negative voltages. J Biol Chem. 2001;276(25):22100-6.

28. Lieb A, Ortner N, Striessnig J. C-terminal modulatory domain controls coupling of voltage-sensing to pore opening in Cav1.3 L-type $\mathrm{Ca}^{2+}$ channels. Biophys J. 2014;106(7):1467-75.

29. Ortner NJ, Bock G, Dougalis A, Kharitonova M, Duda J, Hess S, et al. Lower Affinity of Isradipine for L-Type $\mathrm{Ca}^{2+}$ Channels during Substantia Nigra Dopamine Neuron-Like Activity: Implications for Neuroprotection in Parkinson's Disease. J Neurosci. 2017;37(28):6761-77.

30. Wu J, Yan Z, Li Z, Qian X, Lu S, Dong M, et al. Structure of the voltage-gated calcium channel Cav1.1 at 3.6 A resolution. Nature. 2016;537(7619):191-6.

31. Min BJ, Kim N, Chung T, Kim OH, Nishimura G, Chung CY, et al. Whole-exome sequencing identifies mutations of KIF22 in spondyloepimetaphyseal dysplasia with joint laxity, leptodactylic type. Am J Hum Genet. 2011;89(6):760-6.

32. Ohsugi M, Adachi K, Horai R, Kakuta S, Sudo K, Kotaki H, et al. Kid-mediated chromosome compaction ensures proper nuclear envelope formation. Cell. 2008;132(5):771-82.

33. Fernandes-Rosa FL, Williams TA, Riester A, Steichen O, Beuschlein F, Boulkroun $S$, et al. Genetic spectrum and clinical correlates of somatic mutations in aldosterone-producing adenoma. Hypertension. 2014;64(2):354-61.

34. Pinggera A, Striessnig J. Cav 1.3 (CACNA1D) L-type Ca ${ }^{2+}$ channel dysfunction in CNS disorders. J Physiol. 2016;594(20):5839-49.

35. Scharinger A, Eckrich S, Vandael DH, Schonig K, Koschak A, Hecker D, et al. Cell-type-specific tuning of Cav1.3 $\mathrm{Ca}^{2+}$-channels by a C-terminal automodulatory domain. Front Cell Neurosci. 2015;9:309.
36. Barrett CF, Tsien RW. The Timothy syndrome mutation differentially affects voltage- and calcium-dependent inactivation of Cav1.2 L-type calcium channels. Proc Natl Acad Sci U S A. 2008;105(6):2157-62.

37. Olson PA, Tkatch T, Hernandez-Lopez S, Ulrich S, Ilijic E, Mugnaini E, et al. Gprotein-coupled receptor modulation of striatal Cav1.3 L-type $\mathrm{Ca}^{2+}$ channels is dependent on a Shank-binding domain. J Neurosci. 2005;25(5):1050-62.

38. Limpitikul WB, Dick IE, Ben-Johny M, Yue DT. An autism-associated mutation in Cav1.3 channels has opposing effects on voltage- and $\mathrm{Ca}^{2+}$-dependent regulation. Sci Rep. 2016;6:27235.

39. Helton TD, Xu W, Lipscombe D. Neuronal L-type calcium channels open quickly and are inhibited slowly. J Neurosci. 2005;25(44):10247-51.

40. Sinnegger-Brauns MJ, Hetzenauer A, Huber IG, Renstrom E, Wietzorrek G, Berjukov $\mathrm{S}$, et al. Isoform-specific regulation of mood behavior and pancreatic beta cell and cardiovascular function by L-type $\mathrm{Ca}^{2+}$ channels. J Clin Invest. 2004;113(10):1430-9.

41. Platzer J, Engel J, Schrott-Fischer A, Stephan K, Bova S, Chen H, et al. Congenital deafness and sinoatrial node dysfunction in mice lacking class D L-type $\mathrm{Ca}^{2+}$ channels. Cell. 2000;102(1):89-97.

42. Liao P, Yu D, Li G, Yong TF, Soon JL, Chua YL, et al. A smooth muscle Cav1.2 calcium channel splice variant underlies hyperpolarized window current and enhanced state-dependent inhibition by nifedipine. J Biol Chem. 2007; 282(48):35133-42

43. Ortner NJ, Striessnig J. L-type calcium channels as drug targets in CNS disorders. Channels (Austin, Tex). 2016;10(1):7-13.

44. Uchida S, Yamada S, Nagai K, Deguchi Y, Kimura R. Brain pharmacokinetics and in vivo receptor binding of 1,4-dihydropyridine calcium channel antagonists. Life Sci. 1997;61(21):2083-90.

45. Akerstrom T, Willenberg HS, Cupisti K, Ip J, Backman S, Moser A, et al. Novel somatic mutations and distinct molecular signature in aldosteroneproducing adenomas. Endocr Relat Cancer. 2015;22(5):735-44.

46. Azizan EA, Poulsen H, Tuluc P, Zhou J, Clausen MV, Lieb A, et al. Somatic mutations in ATP1A1 and CACNA1D underlie a common subtype of adrenal hypertension. Nat Genet. 2013;45(9):1055-60.

47. Omata K, Anand SK, Hovelson DH, Liu C-J, Yamazaki Y, Nakamura Y, et al. Aldosterone-Producing Cell Clusters Frequently Harbor Somatic Mutations and Accumulate With Age in Normal Adrenals. J Endocrine Soc. 2017;1(7):787-99.

48. Nanba K, Omata K, Gomez-Sanchez CE, Stratakis CA, Demidowich AP, Suzuki $\mathrm{M}$, et al. Genetic Characteristics of Aldosterone-Producing Adenomas in Blacks. Hypertension. 2019;73(4):885-92.

\section{Publisher's Note}

Springer Nature remains neutral with regard to jurisdictional claims in published maps and institutional affiliations.

\section{Ready to submit your research? Choose BMC and benefit from:}

- fast, convenient online submission

- thorough peer review by experienced researchers in your field

- rapid publication on acceptance

- support for research data, including large and complex data types

- gold Open Access which fosters wider collaboration and increased citations

- maximum visibility for your research: over $100 \mathrm{M}$ website views per year

At BMC, research is always in progress.

Learn more biomedcentral.com/submissions 